\title{
Carbon fibre sheet moulding compounds with high in- mould flow: linking morphology to tensile and compressive properties
}

Luca M. Martulli ${ }^{1,2}$, Leen Muyshondt ${ }^{2}$, Martin Kerschbaum ${ }^{1}$, Soraia Pimenta ${ }^{3}$, Stepan V. Lomov ${ }^{2}$, Yentl Swolfs ${ }^{2}$

${ }^{1}$ Toyota Motor Europe, Material Engineering, Hoge Wei 33, 1930 Zaventem, Belgium

${ }^{2}$ Department of Materials Engineering, KU Leuven, Kasteelpark Arenberg 44 box2540, B-3001 Leuven, Belgium

${ }^{3}$ meComposites, Department of Mechanical Engineering, Imperial College London, South Kensington Campus, London, SW7 2AZ, UK

*Corresponding author: luca.martulli@toyota-europe.com

\begin{abstract}
In-mould flow during manufacturing of Sheet Moulding Compounds (SMCs) heavily affects the material microstructure and its mechanical properties. This influence is studied here for carbon SMCs on panels compression moulded with limited charge coverage. The high in-mould flow caused severe in-plane tow distortions, while their planarity was preserved. Flow induced fibre orientation plays a paramount role in the material failure, whereas local manufacturing defects had no discernible influence. The properties difference between specimens with preferential orientation of $0^{\circ}$ and $90^{\circ}$ was $150 \%$ for tensile stiffness, $260 \%$ for tensile strength, $120 \%$ for compressive stiffness and $32 \%$ for compressive strength. The compressive strength and failure strain for $45^{\circ}$ and $90^{\circ}$ specimens were higher than those for tension, and comparable for $0^{\circ}$ specimens. Compressive and tensile moduli were similar for specimens with the same orientation. A clear link between SMCs manufacturing and mechanical performance is highlighted, together with its implications on structural design.
\end{abstract}

Keywords: A. Discontinuous Reinforcement; D. Microstructural analysis; D. CT analysis; E. Compression moulding

\section{Introduction}

High-performance carbon-fibre-reinforced composites have already conquered many industrial sectors, like aerospace and motorsport. High-volume car manufacturers, however, rely more on short fibre composites, thanks to their advantageous processability and lower cost. Despite being more suitable for high volume industries, 
those materials show lower performance than their continuous fibre counterparts, and cannot replace metals in structural automotive parts.

Tow-based discontinuous composites (TBDCs), like Carbon Fibre Sheet Moulding Compounds (CF-SMCs), can be a good solution to this problem. CF-SMCs are made of chopped carbon fibre tows dispersed in a partially cured thermoset resin; sheets of prepreg material are made in this way, and then compression moulded into the final desired shape. CF-SMCs offer an excellent compromise between the processability and formability of short fibre composites and high mechanical properties of laminated composites [1-3]. In these materials the reinforcement tows generally have a high aspect ratio; this allows their discontinuous nature to have limited effects on their stiffness [1,4-6]. In addition, the compression moulding manufacturing process enables complex shapes to be with low cycle times [7].

Plenty of work is available regarding the mechanical characterisation of randomly oriented TBDCs [2,8-14]. These TBDCs usually have a 2D isotropic behaviour, with properties being different only in the out-of-plane direction (perpendicular to the tows plane) $[8,10-12,14]$. Their tensile and compressive stiffnesses are comparable to those of Quasi-Isotropic (QI) laminates, while their strengths are lower [2,8,9,14,15]. Due to the high material variability, stiffness and strength display significant scatter. Tensile failure is mainly matrix dominated, triggered in tows oriented transverse to the load direction $[1,2,8]$. Johanson et al. [13] suggested that the preferential site for failure initiation are the ends of the tows aligned with the load direction that overlap with transverse strands. When tows oriented along the load direction are present in the failure zone, pull-out or fibre failure can be observed depending on the tow length $[1,2,8]$. Those failure mechanisms are secondary, and tensile strength of TBDCs is mainly matrix-dominated $[1,2]$. Compressive failure is mainly dominated by tow debonding/delamination, combined with tow breakage $[1,2,8]$. Note that randomoriented TBDCs have a compressive strength similar or higher than the tensile one. The reason for this lies in a mainly matrix-dominated TBDCs strength, that is thus less sensitive to positive (tensile) or negative (compressive) load direction [2].

Strength of TBDCs was improved by using a Ultra-Thin Chopped carbon fibre Tape reinforced Thermoplastic (UT-CTT) material system [5,15-18]. UT-CTT is made with a wet-type paper making process to preserve the tow integrity and to ensure property distribution. Tow distortion, out-of-plane waviness and presence of defects is then lower than conventional compression moulded SMCs, thus explaining this difference. However, this had no impact on stiffness, for which the QI laminate constitutes an upper limit [15].

Notch-insensitivity was reported in literature as well [19-21]: when performing open hole tension and compression tests, a significant number of specimens failed away from the hole. The cause of this phenomenon is considered to be inherent stress 
concentrations inside the material $[19,20]$, together with generally high values of fracture toughness [21].

Nearly all of the literature on TBDCs focuses on randomly oriented fibres with uniform orientation distribution. Such a focus was driven by the industrial interest for the isotropy and the faster manufacturing achievable with such a configuration. There is a lack of studies regarding the effects of a high amount of material flowing inside the mould. The material flow inside the mould has a major impact on the fibre orientation for injection moulded short fibres [22,23] and compression moulded composites $[10,14,24,25]$. With the manufacturing of increasingly complex components, ensuring a complete charge coverage in the mould cannot be possible; therefore, regions with highly oriented fibres will inevitably form [26].

Le et al. [24] identified two skin layers in the high flow glass fibre SMC in which the tows were broken into individual fibres and low fibre content was found. This was attributed to high shear in the vicinity of the mould during closure. These zones were no larger than two hundreds of microns, and in the core the tows were still intact and recognisable. Shearing was thus considered negligible, and a plug flow mode was suggested to describe well the flow inside the mould. Tows inside the core were subjected to significant bending, widening and flattening. The authors, however, did not investigate further the effects of their findings on the mechanical performance of the SMC. A similar work was performed on carbon SMC by Kite et al. [27]. The authors observed high tow distortion subsequent to high material flow. Moreover, combining Digital Image Correlation (DIC) with micro Computed Tomography $(\mu \mathrm{CT})$ observations, they observed higher strain in tows oriented perpendicularly to the load. The work was, however, focused on warpage effects, and did not investigate the effects on mechanical performance and failure behaviour in more detail.

A deeper analysis for carbon SMC was made by Evans et al. [10]: the authors compression moulded plates with charge coverage ranging from $40 \%$ to $100 \%$. Specimens cut parallel and perpendicular to the flow direction were tested in tension. An in-plane anisotropic response was observed for the lower charge coverage; the gap between aligned and transverse material response was progressively reduced increasing the coverage, until in-plane isotropy was reached for the $100 \%$ case. Their objective, however, was to develop a new carbon fibre moulding compound with an automated spray deposition process, while CF-SMC was used as reference material. For this material, the investigation was thus limited to tensile properties evaluation, and no study on failure mechanisms and their microstructural causes was performed.

Nony-Davadie et al. [28] have recently investigated the anisotropic response of CFSMC induced by the high flow during compression moulding. They performed quasistatic tensile tests on CF-SMC specimens having an induced preferential orientation of $0^{\circ}, 45^{\circ}$ and $90^{\circ}$, and on specimens with no in-mould flow. However, even those no-flow 
specimens showed an in-plane anisotropy as well. This was attributed to a small fibre orientation induced by the early stage manufacturing of the prepreg sheets. SEM fractography and $X$ ray radiography were used to investigate the failure behaviour, reporting two damage mechanisms at different scales: intra-tow and inter-tow cracking. The overall failure of the material was attributed to the inter-tow cracking. Radiographic analysis was only done post-mortem, and thus no investigation on the effects of the flow of the morphology of the material was done. As a result, no link between morphology and mechanical properties was studied. Moreover, the investigation on the failure mechanisms suffered from the limitations of the $\mathrm{X}$ ray radiography, which can not reveal as much information as $\mathrm{X}$ ray $\mu \mathrm{CT}$.

In the present work, we investigate the relation between the microstructure and mechanical properties of high flow CF-SMC. Several plates are manufactured with low charge coverage, thus ensuring a high amount of material flowing in the mould.

Specimens are cut out of the plates at different orientation in relation to the main flow direction, and they are tested quasi-statically in tensile and compression. Before and after the tests, $\mathrm{X}$ ray computed tomography was used to investigate the morphologic features due to manufacturing process and loading. Fibre orientation was measured using VoxTex software [29]. SEM fractography was used to support the observations of the $\mathrm{X}$ ray $\mu \mathrm{CT}$ analysis of fractured samples.

\section{Materials \& methods}

\subsection{Materials and production}

Mitsubishi Chemical Carbon Fiber and Composites GmbH's STR120N131 [30] was used to manufacture all the specimens used in this research. This is made with a vinyl ester resin reinforced with 53\% weight fraction of TR50S-15L [31] carbon fibre chopped strands. The strands have a length of $25.4 \mathrm{~mm}$. Tows width and thickness are subject to higher variation due to manufacturing process, but their average values are 8 $\mathrm{mm}$ and $0.115 \mathrm{~mm}$ respectively (estimation from supplier). The filament count was $15 \mathrm{k}$ per tow and the properties of the fibres are reported in Table 1, as provided by the supplier.

Table 1: Property of the carbon fibres [31]

\begin{tabular}{|c|c|c|c|}
\hline Strand Tensile & Strand Tensile & Elongation & Fibre diameter \\
\hline $4900 \mathrm{MPa}$ & $240 \mathrm{GPa}$ & $2.0 \%$ & $6.8 \mu \mathrm{m}$ \\
\hline
\end{tabular}

Several plates were compression moulded with dimensions $450 \mathrm{~mm} \times 450 \mathrm{~mm}$, and a thickness of $2.5 \mathrm{~mm}$. The procedure is illustrated in Fig. 1.a and Fig.1.b. The moulding temperature, pressure and time was $141.5^{\circ} \mathrm{C}, 215$ bar and $180 \mathrm{~s}$ respectively. The initial charge, made of six sheets of prepreg material, occupied about $20 \%$ of the 
available cavity. This was done to promote significant flow in the compression moulding phase, and hence reorient the fibres along the flow direction. Specimens were then waterjet-cut from the upper region of the plates at angles of $0^{\circ}, 45^{\circ}$ and $90^{\circ}$ (Fig. 1.c, Fig. 1.d and Fig. 1.e), with respect to the main flow direction. For the rest of this paper, they will be referred to as " 0 ", " $45^{\circ}$ " and " $90^{\circ}$ " samples respectively. The specimens where cut at least $25 \mathrm{~mm}$ far from the plate borders, to avoid any mould edge effect.

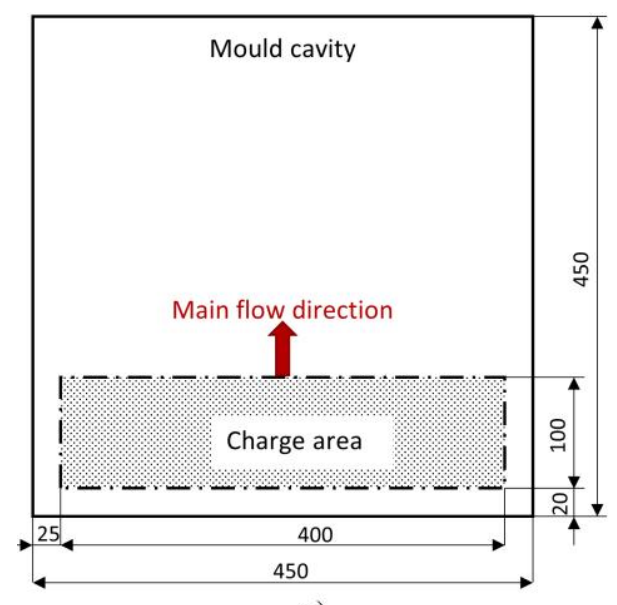

a)

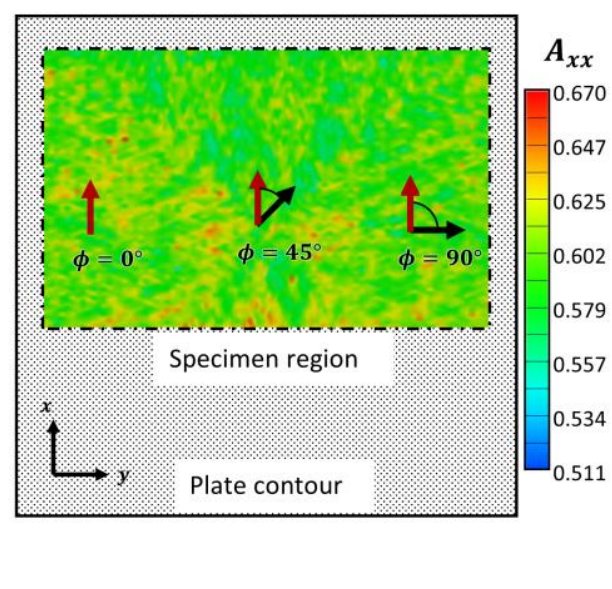

b)

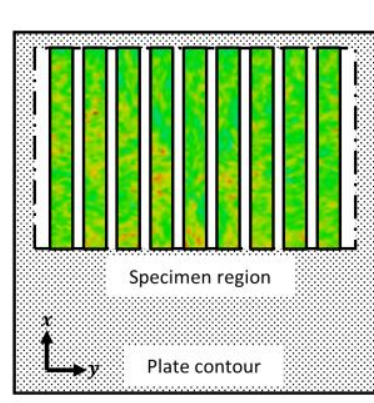

c)

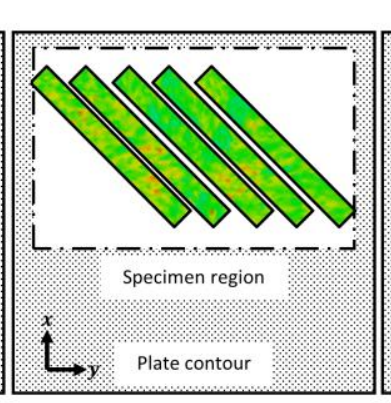

d)

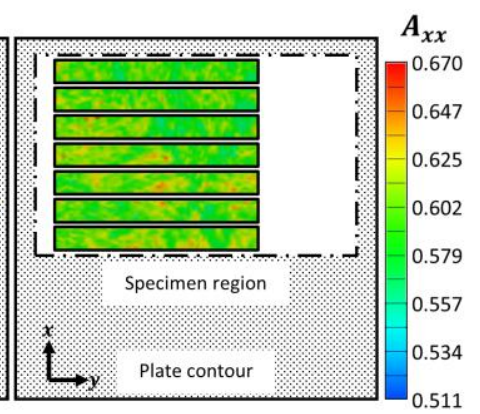

e)

Fig. 1 Compression moulding of plates and specimens manufacturing: a) charge placement before the mould is closed, b) moulded plate, and cutting location of the c) $0^{\circ}$, d) $45^{\circ}$ and e) $90^{\circ}$ specimens . Predictions of the $\mathrm{x}$ component of the orientation tensor inside the specimens' region are shown.

To assess the variation of fibre orientation inside the specimen cutting region, Moldex3D simulations were performed. Fig. 1.b shows the field of $x$ component of the orientation tensor [32]. The Moldex3D fibre orientation model [33] was calibrated to obtain an average orientation tensor in the specimen region as close as possible to the one measured and reported in section 3.1. The calibrated parameters are: the fibre-fibre interaction parameter $\mathrm{C}_{\mathrm{I}}$ equals to 0.03 , the fibre-matrix interaction parameter equals to 0.9 and the $\alpha$ parameter is 0.7 . The software predicts a less oriented state as flow progresses from the charge area to the opposite border. This has less important implications on the $0^{\circ}$ and $45^{\circ}$ specimens, as their length spans the entire $x$ direction of the region (see Fig. 1.c and Fig. 1.d). This is not true for the $90^{\circ}$ specimens (see Fig. 
1.e), and therefore, the tested specimens were cut all from different locations. In the specimen region, the maximum and minimum values of the $x$ component of the orientation tensor were 0.67 and 0.55 respectively.

\subsection{Tensile tests}

Quasi-static tensile tests were performed according to ASTM D3039 [34] on an Instron 4505. The specimens were $250 \mathrm{~mm}$ x $25 \mathrm{~mm}$ in size, and they were tested at a gauge length of $150 \mathrm{~mm}$. The displacement rate was set to $1 \mathrm{~mm} / \mathrm{min}$. A $100 \mathrm{kN}$ load cell was used to measure the load. A white speckle pattern was applied to the front specimen surface. The surface strain was measured using digital image correlation of this pattern, as often suggested for this kind of material (e.g. [9]). Six, five and six samples were tested for the $0^{\circ}, 45^{\circ}$ and $90^{\circ}$ case, respectively.

The tensile modulus was calculated in a strain range of $25 \%$ to $50 \%$ of ultimate strain, as suggested by the standard for materials failing at strain below $0.6 \%$.

\subsection{Compressive tests}

Quasi-static compressive tests were performed according to ASTM D3410 [35] on an Instron 5985. The specimens were $125 \mathrm{~mm} \times 25 \mathrm{~mm}$ in size, and they were tested at a gauge length of $20 \mathrm{~mm}$. This length should be short enough to avoid Eulerian buckling [35] and to ensure a correct material characterisation [36]. The displacement rate was set to $1 \mathrm{~mm} / \mathrm{min}$. A $250 \mathrm{kN}$ load cell was used to measure the load. A white speckle pattern was applied to both surfaces of the specimen. The surface strain was measured using digital image correlation on both sides of the specimen. This allowed the evaluation of the percent bending in the specimens according to:

$$
B_{y}=\frac{\epsilon_{\text {front }}-\epsilon_{\text {back }}}{\epsilon_{\text {front }}+\epsilon_{\text {back }}} \times 100
$$

Specimens that showed more than $10 \%$ of bending in the second half of their stressstrain curve were rejected. Six specimens were tested for the $0^{\circ}$ (five valid, one rejected) and $90^{\circ}$ (four valid, two rejected) case, while nine for the $45^{\circ}$ (three valid, six rejected).

The compressive modulus was calculated in a strain range of $0.1 \%$ to $0.3 \%$.

\section{$2.4 X$ ray micro-CT}

Micro-CT scans were performed with a GE Nanotom X ray computed tomography system. The voltage was set to $60 \mathrm{kV}$ and the current to $290 \mathrm{~mA}$ for the scans of the oriented specimens. The resolution of the scans was selected to be $12.5 \mu \mathrm{m}$, which allows scanning the entire width of the samples. The entire gauge length of two $0^{\circ}$ specimens and two $90^{\circ}$ specimens was scanned before the tensile tests. After the tests, the specimens were scanned again, but only in the failure location. For the full gauge 
length scans, several scans were performed at different heights and stitched together. The entire gauge length of two $0^{\circ}$ specimens and two $90^{\circ}$ specimens was scanned before and after compression tests. This was short enough to be analysed within a single scan.

The $\mathrm{X}$ ray scans performed before the tests are first used to measure the fibre orientation in the material. Five scans, covering the full gauge length of a $0^{\circ}$ and one of a $90^{\circ}$ specimens, were analysed with VoxTex [29] for this purpose. Gaussian blurring was applied to mitigate the noise [26] and to increase the accuracy of the gradient-based method [26,37].

To have a better understanding of the SMC microstructure, an additional scan at resolution of $4 \mu \mathrm{m}$ was also performed on a $0^{\circ} \mathrm{SMC}$ sample. To allow such a high resolution, the sample was cut to $9 \mathrm{~mm} \times 9 \mathrm{~mm} \times 2.5 \mathrm{~mm}$ dimensions.

Moreover, seven patches ( $40 \mathrm{~mm}$ x $80 \mathrm{~mm})$ of prepreg sheets were stacked and cured in an oven at $80^{\circ}$ for 24 hours. This stack was then $\mathrm{X}$ ray scanned to serve as reference for the assessment of the effects of the compression moulding on the material morphology. No fibre orientation measurements are performed on this specimen, as the edges of the numerous voids will bias the results.

\section{Morphology}

The morphology of the material is described using the global coordinate system, as shown in Fig. 1: $x$ direction is the dominant flow direction, $y$ is orthogonal to $x$ in the plane of the plate, $z$ is normal to the plate. The $z$ coordinate is indicated as starting from the bottom surface.

\subsection{Fibre orientation measurements}

Results of the fibre orientation measurements are reported in Table 2 in terms of orientation tensor [32] for each scan. The failure location of the tensile tests is reported in red, and will be later discussed in section 5. The orientation tensors representing the whole specimens were calculated as follows: the VoxTex-defined fibre orientations in voxel elements of all five scans were combined in one aggregate sampling and the orientation tensor was calculated based on this sampling as instructed in [32].

Table 2: Orientation tensors measured for each scan for a $0^{\circ}$ and a $90^{\circ}$ specimen. In red, the failure location after tensile tests.

\begin{tabular}{|c|ccc|}
\hline & $0^{\circ}$ & $90^{\circ}$ \\
\hline \multirow{3}{*}{ Scan 1 } & $\left(\begin{array}{ccc}0.647 & 0.031 & -0.007 \\
\text { sym. } & 0.335 & 0.005 \\
\text { sym. } & \text { sym. } & 0.018\end{array}\right)$ & $\left(\begin{array}{ccc}0.349 & 0.003 & -0.006 \\
\text { sym. } & 0.641 & 0.011 \\
\text { sym. } & \text { sym. } & 0.009\end{array}\right)$ \\
\hline
\end{tabular}




\begin{tabular}{|c|c|c|c|c|c|c|}
\hline Scan 2 & $\left(\begin{array}{l}0.667 \\
\text { sym. } \\
\text { sym. }\end{array}\right.$ & $\begin{array}{c}-0.011 \\
0.315 \\
\text { sym. }\end{array}$ & $\left.\begin{array}{c}-0.005 \\
-0.001 \\
0.017\end{array}\right)$ & $\left(\begin{array}{l}0.332 \\
\text { sym. } \\
\text { sym. }\end{array}\right.$ & $\begin{array}{c}-0.02 \\
0.658 \\
\text { sym. }\end{array}$ & $\left.\begin{array}{c}0 \\
0.003 \\
0.01\end{array}\right)$ \\
\hline Scan 3 & $\left(\begin{array}{l}0.675 \\
\text { sym. } \\
\text { sym. }\end{array}\right.$ & $\begin{array}{c}0.032 \\
0.312 \\
\text { sym. }\end{array}$ & $\left.\begin{array}{c}0.012 \\
-0.008 \\
0.012\end{array}\right)$ & $\left(\begin{array}{l}0.345 \\
\text { sym. } \\
\text { sym. }\end{array}\right.$ & $\begin{array}{c}-0.12 \\
0.646 \\
\text { sym. }\end{array}$ & $\left.\begin{array}{c}0.005 \\
-0.007 \\
0.008\end{array}\right)$ \\
\hline Scan 4 & $\left(\begin{array}{l}0.693 \\
\text { sym. } \\
\text { sym. }\end{array}\right.$ & $\begin{array}{c}-0.076 \\
0.287 \\
\text { sym. }\end{array}$ & $\left.\begin{array}{c}0.001 \\
-0.008 \\
0.012\end{array}\right)$ & $\left(\begin{array}{c}0.355 \\
\text { sym. } \\
\text { sym. }\end{array}\right.$ & $\begin{array}{c}0.04 \\
0.636 \\
\text { sym. }\end{array}$ & $\left.\begin{array}{c}-0.01 \\
-0.006 \\
0.008\end{array}\right)$ \\
\hline Scan 5 & $\left(\begin{array}{l}0.643 \\
\text { sym. } \\
\text { sym. }\end{array}\right.$ & $\begin{array}{c}-0.078 \\
0.337 \\
\text { sym. }\end{array}$ & $\left.\begin{array}{c}-0.013 \\
-0.008 \\
0.019\end{array}\right)$ & $\left(\begin{array}{l}0.331 \\
\text { sym. } \\
\text { sym. }\end{array}\right.$ & $\begin{array}{c}-0.016 \\
0.66 \\
\text { sym. }\end{array}$ & $\left.\begin{array}{c}-0.012 \\
0.003 \\
0.008\end{array}\right)$ \\
\hline Specimen & $\left(\begin{array}{c}0.668 \\
\text { sym. } \\
\text { sym. }\end{array}\right.$ & $\begin{array}{c}0.019 \\
0.316 \\
\text { sym. }\end{array}$ & $\left.\begin{array}{c}-0.003 \\
0.001 \\
0.015\end{array}\right)$ & $\left(\begin{array}{c}0.342 \\
\text { sym } \\
\text { sym }\end{array}\right.$ & $\begin{array}{c}0.024 \\
0.65 \\
\text { sym. }\end{array}$ & $\left.\begin{array}{c}0 \\
0.003 \\
0.008\end{array}\right)$ \\
\hline
\end{tabular}

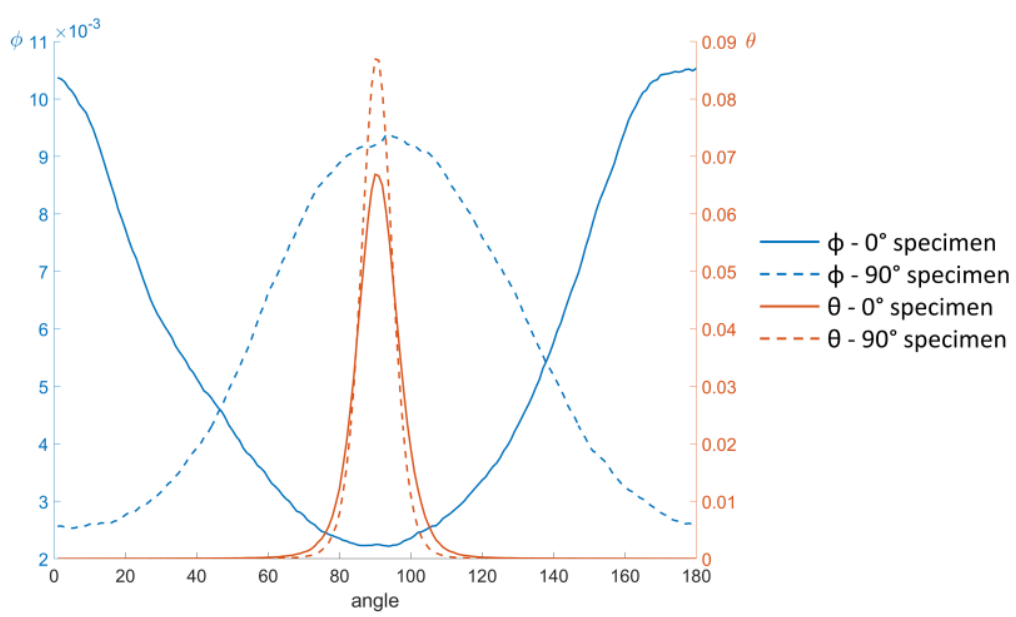

Fig. 2. Fibre orientation distribution functions for the $0^{\circ}$ and for the $90^{\circ}$ specimens.

The orientation distribution functions for the $0^{\circ}$ and $90^{\circ}$ specimens are shown in Fig. 2. For both of them, the out-of-plane angle $\theta$ shows a variance similar to that observed in $[17,18]$ for UT-CTT. For thin panels it is thus reasonable to assume that the planar nature of TBDC is preserved irrespective of the amount of flow inside the mould. This is true even when dealing with highly distorted tows (see section 3.2). By comparison, the dispersion of the in-plane orientation $\varphi$ was much larger, even if a clear main orientation is present. Finally, the difference in the peak values of $\varphi$ and $\theta$ between the two specimens is believed to be caused by the variability of the orientation process.

Compared to the measured orientation tensors, the average one predicted by Moldex3D was accurate (see Fig. 1). This, however, came as no surprise, since those components were used for the calibration of the orientation model itself. The difference of the 
extreme values of the orientation tensor components, instead, arises from the different sizes of the averaging volumes. Remembering that orientation tensors are properties averaged per volume, in Fig. 1, the values are averaged per mesh element (few $\mathrm{mm}^{3}$ ). In Table 2, they are averaged over a volume of approximately $25 \mathrm{~mm}$ x $30 \mathrm{~mm}$ x $2.5 \mathrm{~mm}$.

\subsection{Defects observations}

Fig. 3 shows $\mu \mathrm{CT}$ slices of the unprocessed SMC stack and a $0^{\circ}$ and a $90^{\circ}$ specimens. In the prepreg stack, the tows have a net rectangular shape, with fibres mostly straight. In contrast, the flow of material during the compression moulding has distorted the tows in the manufactured specimens both in-plane and out-of-plane. Although two adjacent tows can still be distinguished, the tows have lost their initial shape almost everywhere.

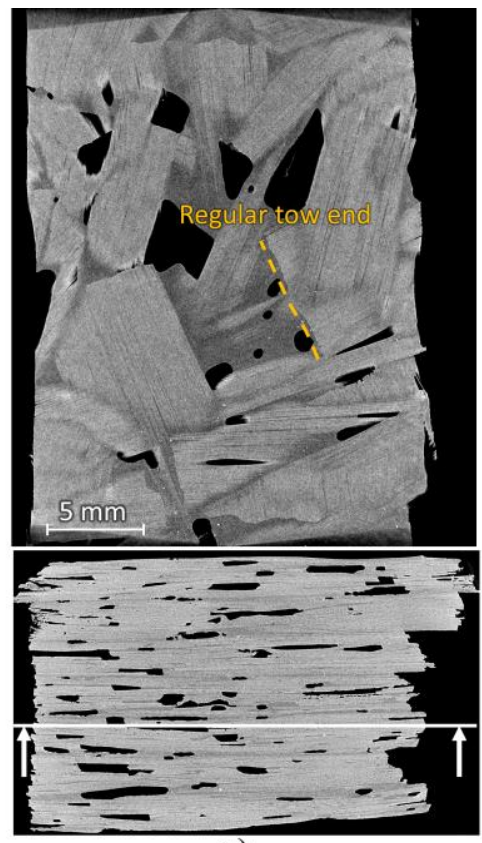

a)

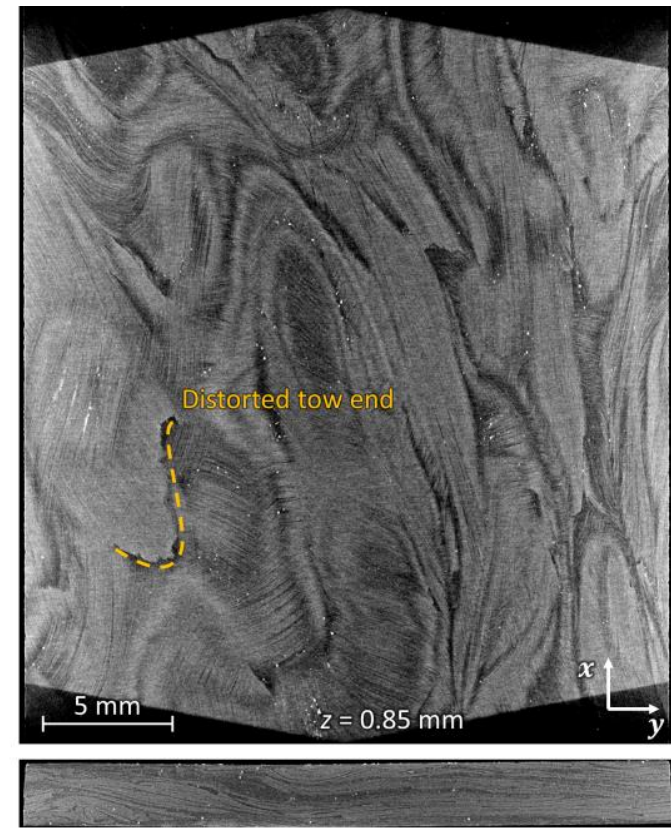

b)

Fig. 3. $\mu \mathrm{CT}$ scans of a) unprocessed prepreg stack and b) a $0^{\circ}$ specimen, for which the flow direction is along $\mathrm{x}$-axis.

Out-of-plane deformation causes tow waviness, which is almost absent in the unprocessed stack. Swirls are also created: Fig. 4.a shows a tow whose thickness has increased up to $0.52 \mathrm{~mm}$. As a comparison, the standard thickness for the tows range from 0.08 to $0.15 \mathrm{~mm}$, as indicated by the manufacturer. Fig. 4.b shows a wrinkled tow, which is a sign of intense deformation. Despite the high distortion, the tows are rarely split into individual fibres, and their meso-structural entity still exists. 


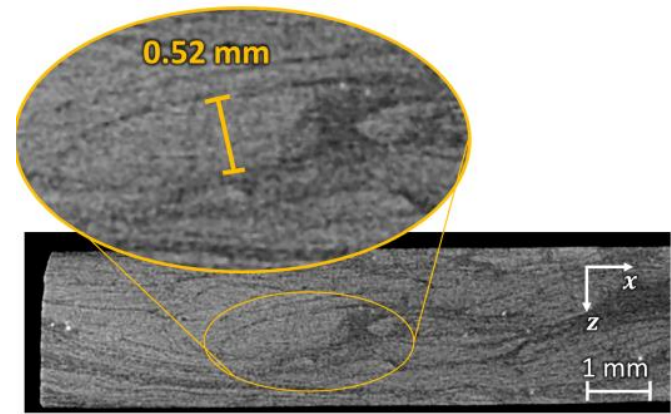

a)

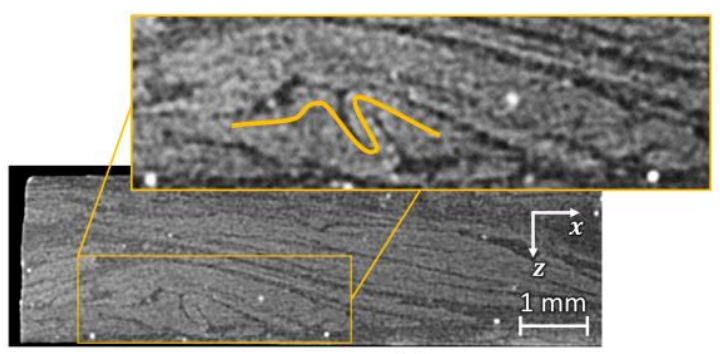

b)

Fig. 4. Flow induced defects observed in the cross section of a $90^{\circ}$ specimen: a) tow thickened by a swirl and b) wrinkled tow.

Within $200 \mu \mathrm{m}$ from the top and bottom surfaces of the panel, however, tow distortion can be much more intense. The tows tend to disintegrate into individual fibres. This feature is evident in the $4 \mu \mathrm{m}$ resolution scan. Skin and core observed in these scans are shown in Fig. 5. Compared to the observations of Le et al. [24], tows in the skin layer of carbon SMC are less distorted than the ones in the skin of glass SMC. Higher tow integrity in the core is caused by less shear stress arising in the core rather than in the outer skins; moreover, it can suggest a plug-like flow into the mould cavity of the uncured SMC. Indeed, the prepreg stack do not show such a feature, confirming it is created upon manufacturing.

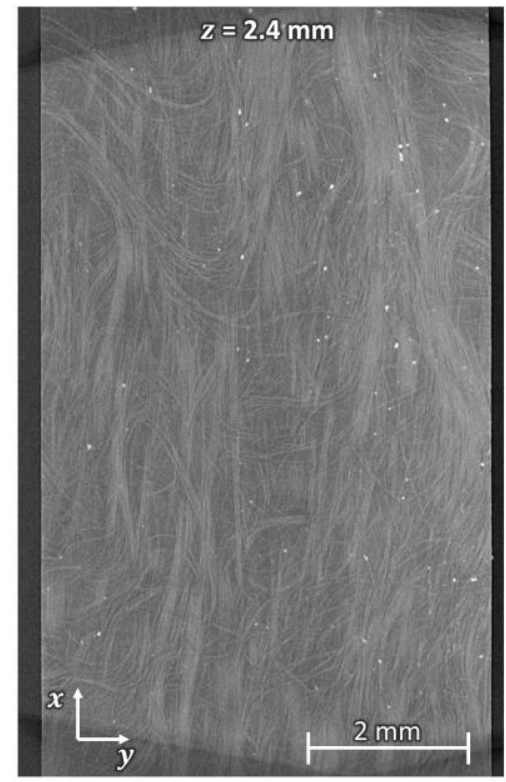

a)

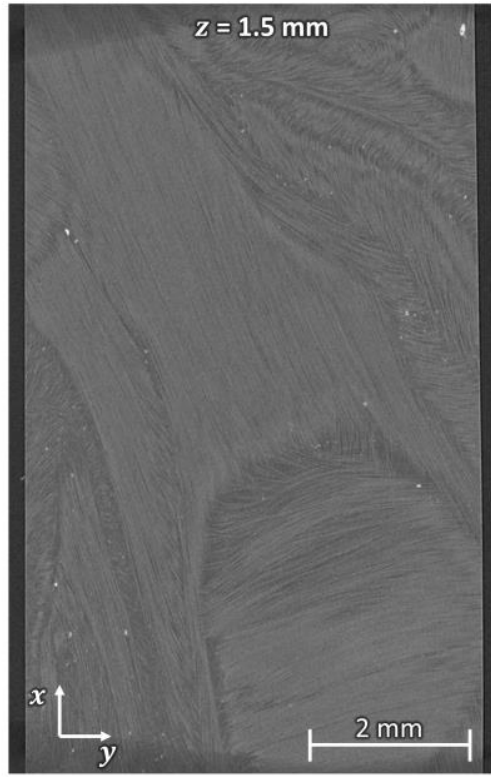

b)

Fig. 5. In-plane slices at $4 \mu \mathrm{m}$ resolution, skin and core evidence: a) $0.1 \mathrm{~mm}$ and b) $1 \mathrm{~mm}$ from the specimen's top surface. Flow direction is along $\mathrm{x}$-axis. 
Other defects that appear to have formed during compression moulding are resin pockets, voids and cracks. In Fig. 6, three main defect areas were observed in a single specimen; the defects areas are described in detail in Fig. 7. Slices of zone A are shown in Fig. 7.a; different slicing planes are used to give a 3D description of the defect. The centre of the crack appears to be a spherical defect, from which many delamination-like cracks originate. The spherical shape suggests the defect might be a void caused by air trapped by the high amount of flow [38,39]. Indeed, many voids are present before the compression moulding in the unprocessed stack (see Fig. 3). The combination of smooth and sharp crack profiles suggests that the crack alternatively takes the form of tow/matrix debonding and matrix cracking. This is also observable in Fig. 7.b, where four in-plane slices are shown, each $187.5 \mu \mathrm{m}$ deeper than the previous. Looking at Fig. 7.a and Fig. 7.b, the voids and cracks seems to affect a low fibre content area (darker regions, where no tows are clearly visible). Starting from the centre of the Fig. 6, another resin pocket (highlighted with a dashed line) extends up until zone B; here (see Fig. 7.c) other cracks are observed where the resin rich area becomes larger. The sharp profile of the crack confirms that those cracks affects mainly the matrix. However, as shown in section BB of Fig. 7.c, they end in a smoother way, suggesting that they propagate as tow/matrix debonding. Finally, smaller cracks are observed in zone C, in Fig. 7.d. Interestingly, these cracks appear to be inside the tow, and they follow the fibre profile and orientation.

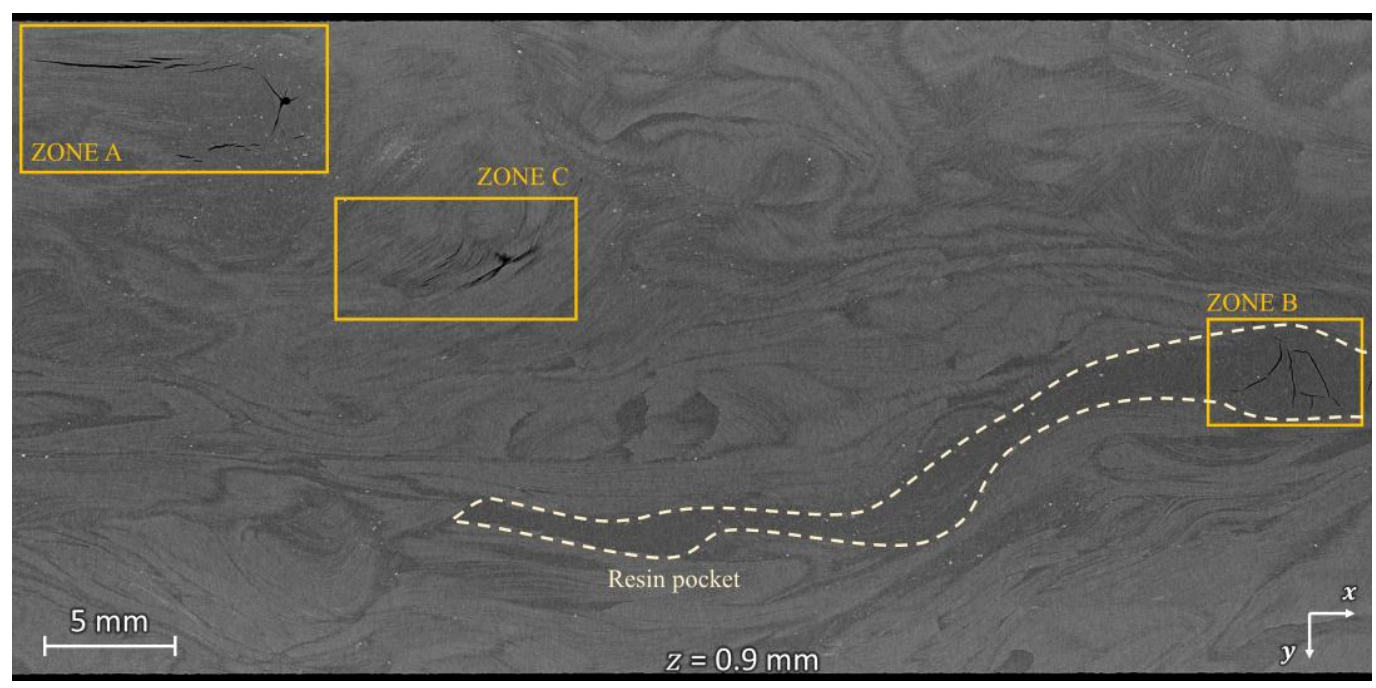

Fig. 6. Defects identified in one of the scanned $0^{\circ}$ specimens before testing. 

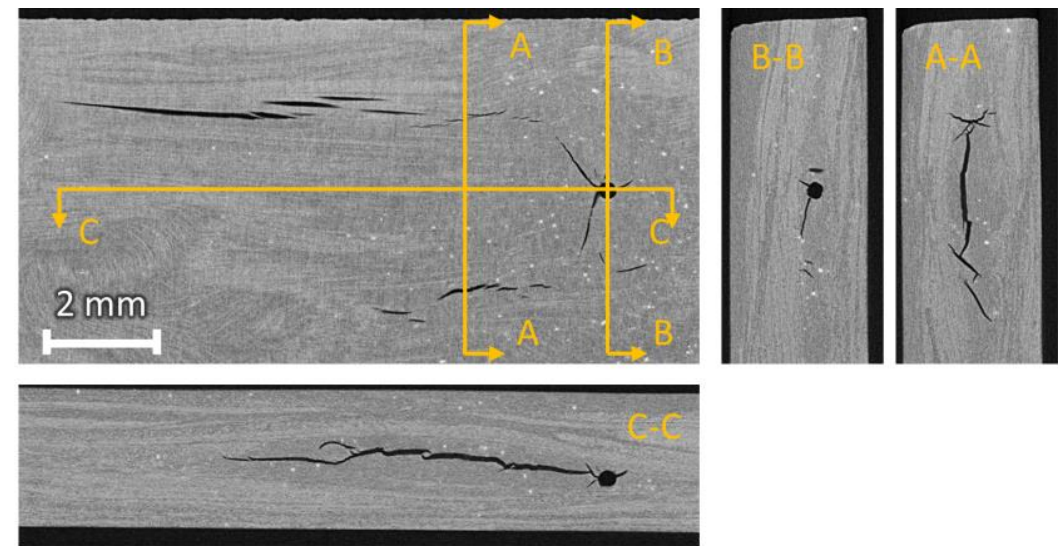

a)
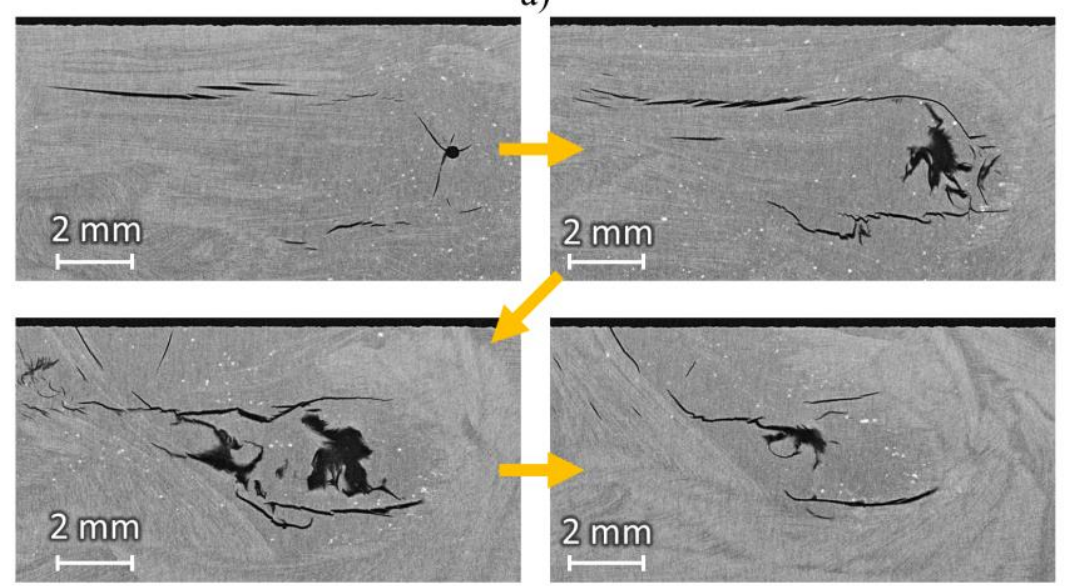

b)
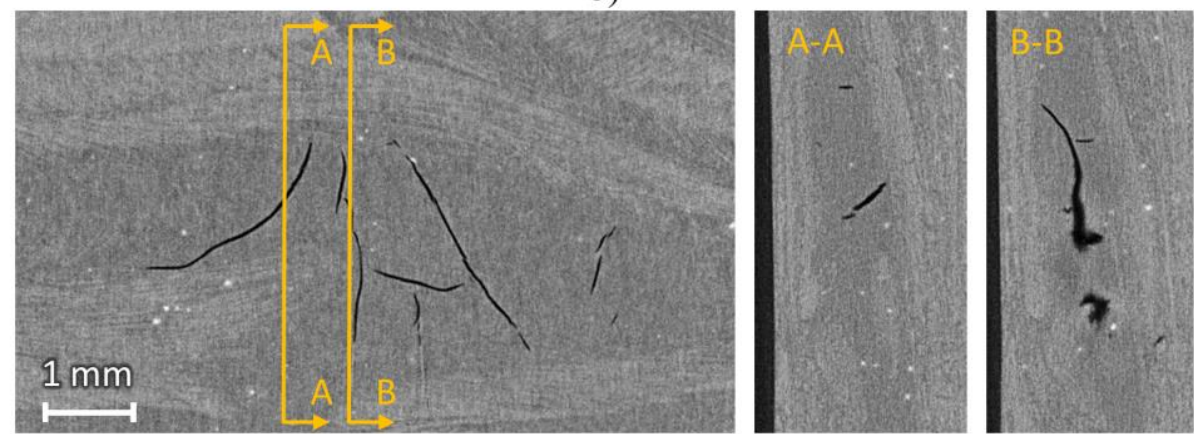

c)
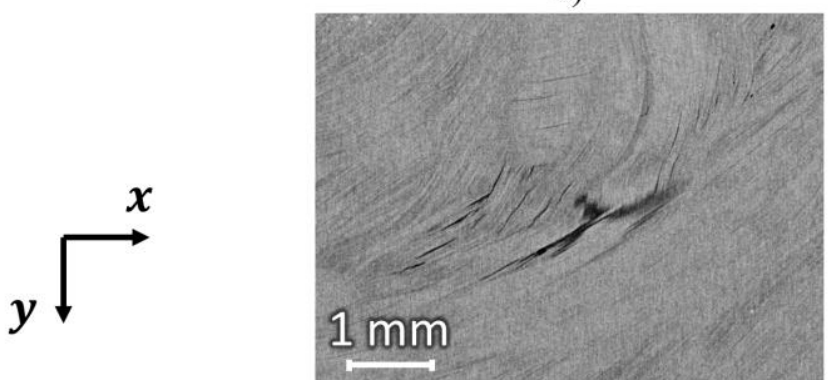

d)

Fig. 7. Gallery of defects observed before testing in Fig. 6: a) 3D observation of void and cracks of zone A. b) The same crack is inspected through the thickness: following the arrows, each slice is $187 \mu \mathrm{m}$ deeper than the previous. c) Matrix cracks in resin pocket in zone B. d) Intra-tow cracks following the fibre local orientation in zone $\mathrm{C}$. 
From the qualitative observations above, it is clear that in-mould flow governs the CFSMC microstructure. For high-flow SMC, the rectangular shape of the tows frequently observed in the literature is lost. Instead, tows appear irregular, mainly in their in-plane shape and partially also in the through-thickness direction. Nevertheless, a certain planarity is still preserved, as observed earlier in section 3.1. Irregularity in the microstructure can result in matrix-rich areas. Voids and cracks can appear in these regions, and spread in the tow interfaces or even throughout a tow. Some cracks were also observed inside a tow, although those cracks appear much smaller.

Given the local nature of observed defects, they will likely influence strength more than stiffness. Although, TBDCs have been reported to be notch insensitive [19-21], no work exist on the effects on such internal micro-defects on their final mechanical performance. This will be addressed in section 4 .

\section{Results of the mechanical tests}

\subsection{Tensile tests}

Fig. 8.a shows the stress-strain curves obtained for the tensile tests. Three groups of curves are clearly identifiable, proving the success of the re-orientation of the fibres during manufacturing. Table 3 lists the values of stiffness, Ultimate Tensile Strength (UTS) and failure strain for the different specimens groups. The 2D randomly oriented case is also shown for comparison, as taken from the supplier datasheet [30] and confirmed in literature [11].

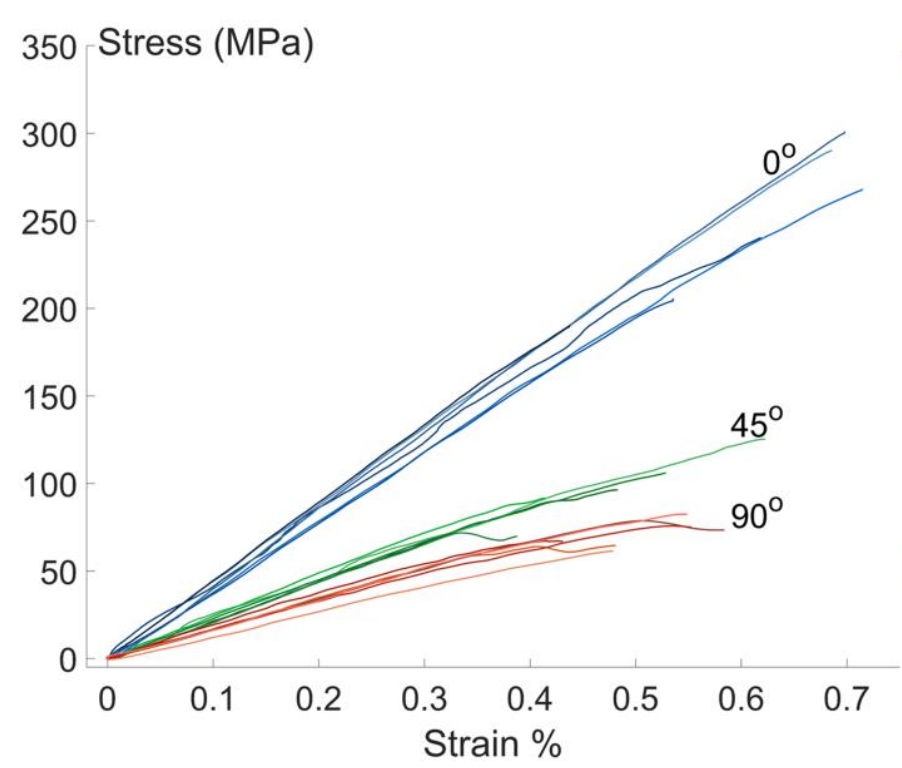

a)

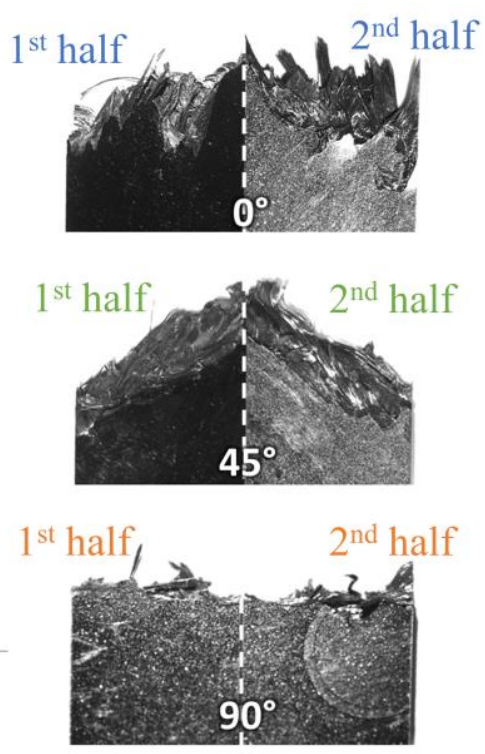

b)

Fig. 8. Tensile tests results: a) stress strain curves of the tensile tests on oriented CF-SMC and b) fracture profiles of the two specimens' halves. 
Table 3: Tensile tests results. The random $2 \mathrm{D}$ orientation data comes from the supplier's datasheet

\begin{tabular}{|c|c|c|c|}
\hline & E $(\mathrm{GPa})$ & UTS $(\mathrm{MPa})$ & Failure strain $(\%)$ \\
\hline $0^{\circ}$ specimens & $42.3 \pm 1.8$ & $255 \pm 38$ & $0.628 \pm 0.097$ \\
\hline $45^{\circ}$ specimens & $22.7 \pm 1.0$ & $103 \pm 13$ & $0.522 \pm 0.079$ \\
\hline $90^{\circ}$ specimens & $17.1 \pm 1.1$ & $71 \pm 7$ & $0.526 \pm 0.058$ \\
\hline Random 2D [30] & 33 & 150 & - \\
\hline
\end{tabular}

In all cases, the specimens remained in one piece even after failure, because of tow intermingling. For one specimen per group, the two halves were separated by manually increasing the cross-head displacement before removing them from the machine, to be analysed with the SEM. Photos in Fig. 8.b were taken with a regular camera after this separation, by putting both halves of the specimens side-by-side. An irregular fracture surface was observed in the $0^{\circ}$ specimens, caused by pulled-out and broken tows in the fracture region. The $45^{\circ}$ and $90^{\circ}$ specimens showed a more regular surface, inclined respectively at $45^{\circ}$ and $90^{\circ}$ with the main load direction.

A large number of pulled-out and broken tows was observed in the $0^{\circ}$ specimens; less than five tows per specimen were found to be pulled-out and broken from the $90^{\circ}$ group. Interestingly, almost all of the tows that were pulled out were also split. Examples of split pulled out tows are reported in Fig. 9.a, 9.b, 9.d, 10.b. and 10.d. It is worth mentioning the matrix damage inside a broken tow in the form of scarps and river markings [40] in Fig. 9.c.

Fig. 10 shows the specimen described in section 3.2, which failed far from all three observed defects; the failure location of that sample was defect free. This observation suggests that strand-based composites are not only insensitive to macroscale notches [19-21], but also to microscale ones and even to small cracks. For this $0^{\circ}$ specimen, again tow breakage and pull-out were observed. The crack spread through the tow/matrix interface (debonding) and along the tow ends (matrix cracking). 

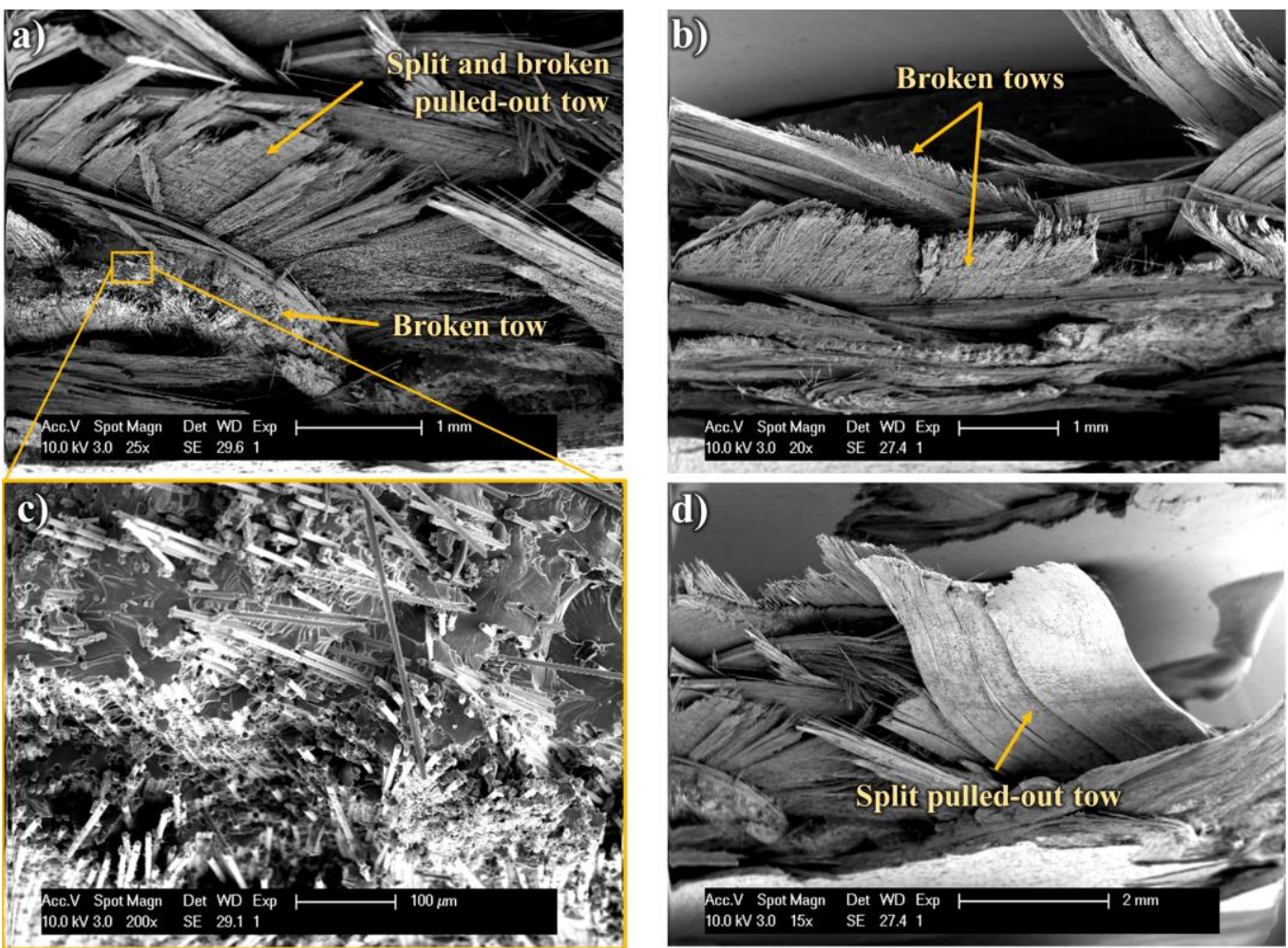

Fig. 9. SEM observation on $0^{\circ}$ sample. The images show fibre dominated failures: $\left.a-b-d\right)$ broken and split tows, split pulled-out ones and the two together. In c) pulled out fibres are visible, as well as matrix damage.

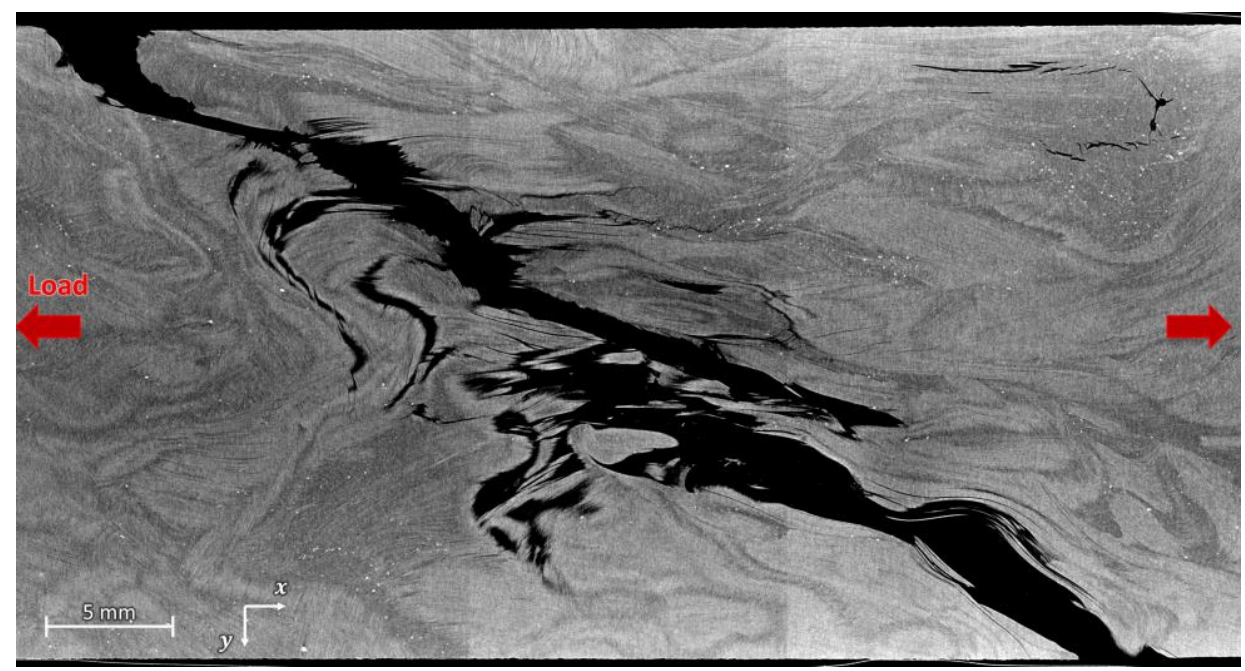

Fig. 10 Failure of $0^{\circ}$ specimen far from defect areas. Red arrows indicate load direction.

SEM observation on the $90^{\circ}$ and $45^{\circ}$ specimens showed the matrix dominated failure reported in literature [2,8]. Fig. 11.a to Fig. 11.d report examples of fibre-matrix debonds, both ductile failure and brittle matrix cracking, and even a broken fibre of a $90^{\circ}$ tow. Other tows (see Fig. 11.e and Fig. 11.f) were observed to be less clean, proving that debonding was not so intense. 

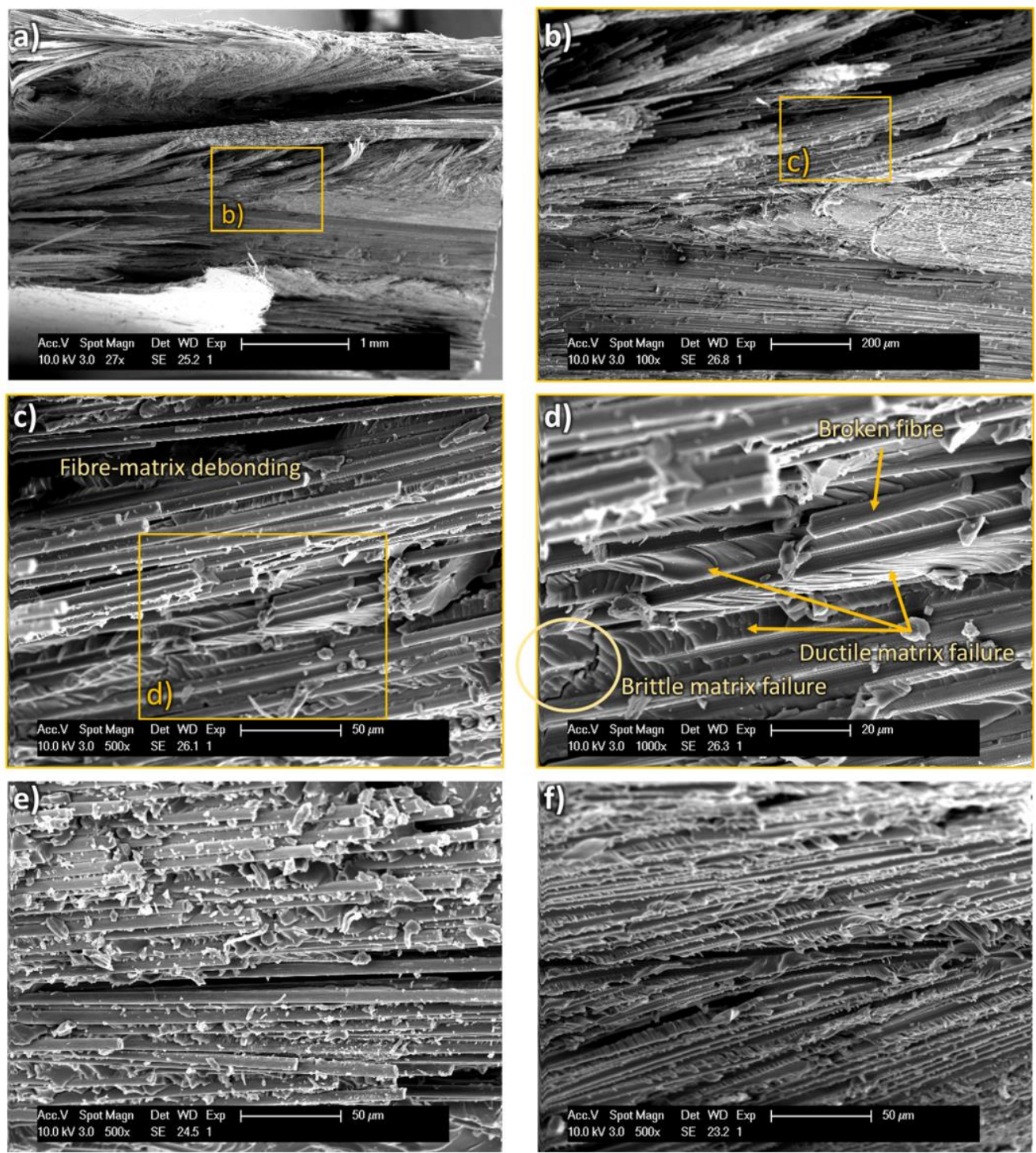

Fig. 11. SEM observation on the $90^{\circ}$ specimens with progressively zoomed-in regions from a) to d), and e-f) less clean fibres.

An interesting observation was the presence of intra-tow cracks in the $90^{\circ}$ specimens. Fig. 12.a shows the failure location, with a crack running through a tow oriented perpendicularly to the load direction. This feature was also observed away from the failure zone, as reported in Fig. 12.b. This feature was not observed in the $0^{\circ}$ scanned samples; however, this might be only due to the lower probability of finding tows perpendicularly oriented to the load direction, rather than to a different redistribution of load due to different fibre orientation. 


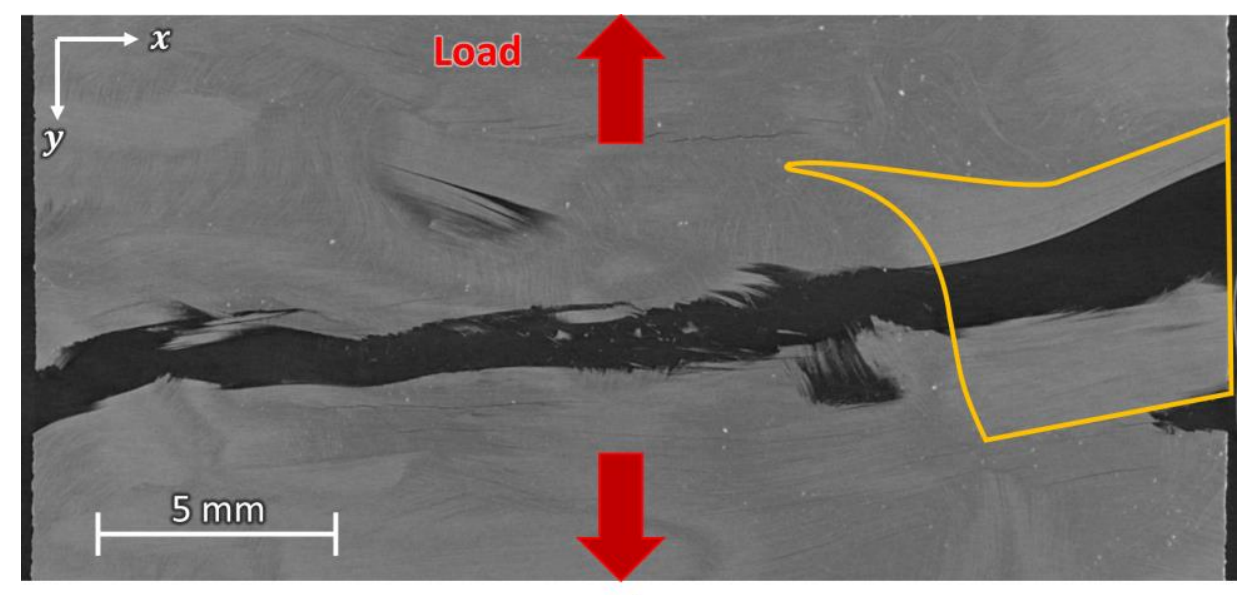

a)

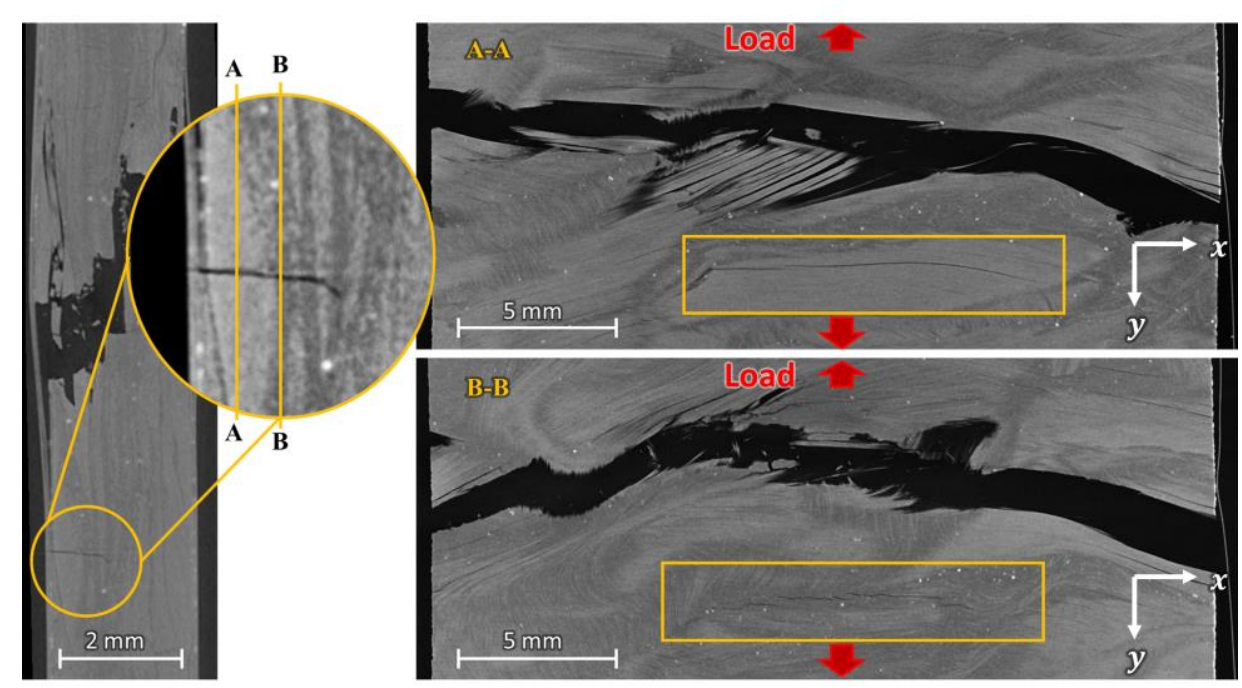

b)

Fig. 12. Transverse cracks in a failed tensile $90^{\circ}$ specimens. a) The failure crack have separated a tow (on the right, highlighted in yellow). b) In slice A-A, the crack is splitting a tow, and has a smooth profile. In slice B-B, crack is irregular, as it is in the matrix. Red arrows indicate load direction.

Fig. 12 can also be used to characterise two different failure modes. When observed inside a tow, the crack appears smooth and linear; this crack is probably an interfacial crack between fibres and matrix. When the same crack is observed in the inter-tow matrix layer, the profile of the crack appear to be irregular, with S-shaped profiles typical of shear failure [40].

In case of very distorted tows, as the one shown in Fig. 13, the failure profile runs along the external interface of the tow. This suggests that, when high in-plane waviness is present, the waved tow acts as an equivalent weaker reinforcement: its equivalent aspect ratio is reduced, as well as its volume fraction and local stiffness. 


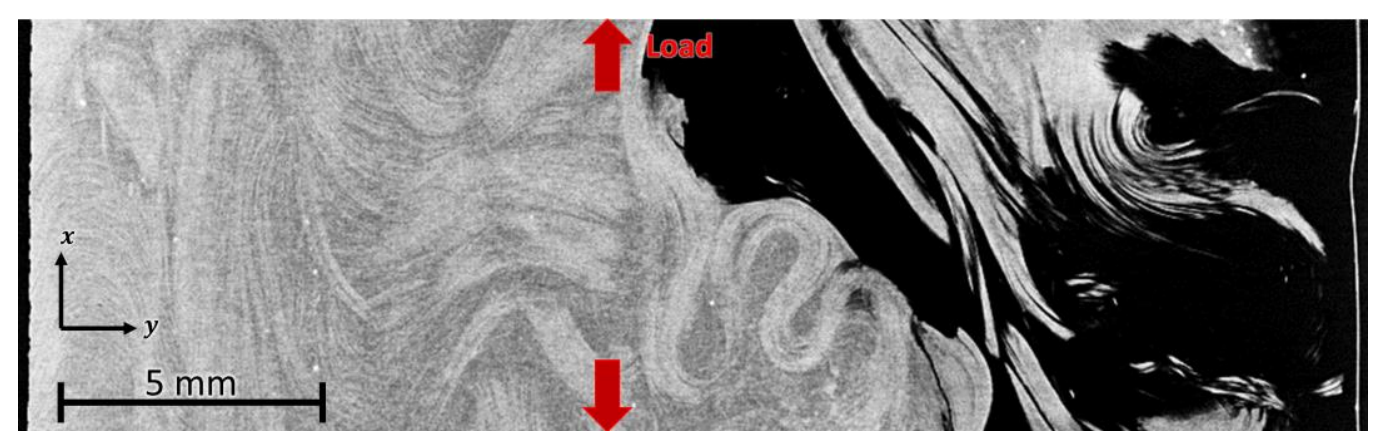

Fig. 13. Crack in a $0^{\circ}$ specimen following the outer contour of a highly distorted tow. Red arrows indicate load direction.

\subsection{Compression tests}

Before analysing the stress-strain diagrams of all the specimens tested in compression, a bending check is performed [35]. Results are shown in Fig. 14.b, where green curves are accepted, and black are rejected. After the check, five specimens out of six were considered to be acceptable for the $0^{\circ}$ case, four out of six for the $90^{\circ}$ cases, while only three out of nine for the $45^{\circ}$ ones. This is due to the intrinsic imbalance of the specimens oriented at $45^{\circ}$. For the $0^{\circ}$ and $90^{\circ}$ specimens, the number of tows oriented at an angle $\varphi$, is statistically the same of the number of tows oriented at $-\varphi$; this is visually represented by the fibre orientation distribution function in Fig. 2. The $45^{\circ}$ specimens are instead characterised by an asymmetric fibre orientation distribution function that peaks at either $+45^{\circ}$ or $-45^{\circ}$.

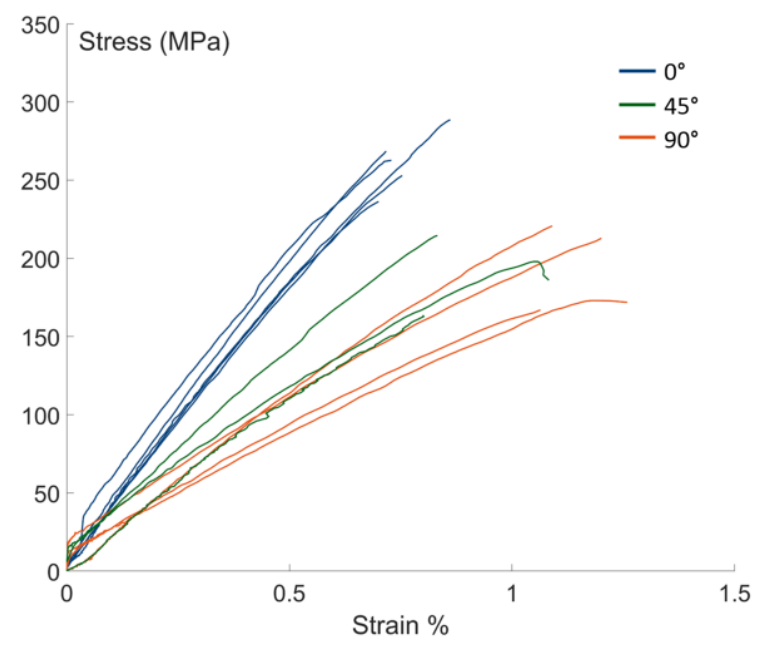

a)

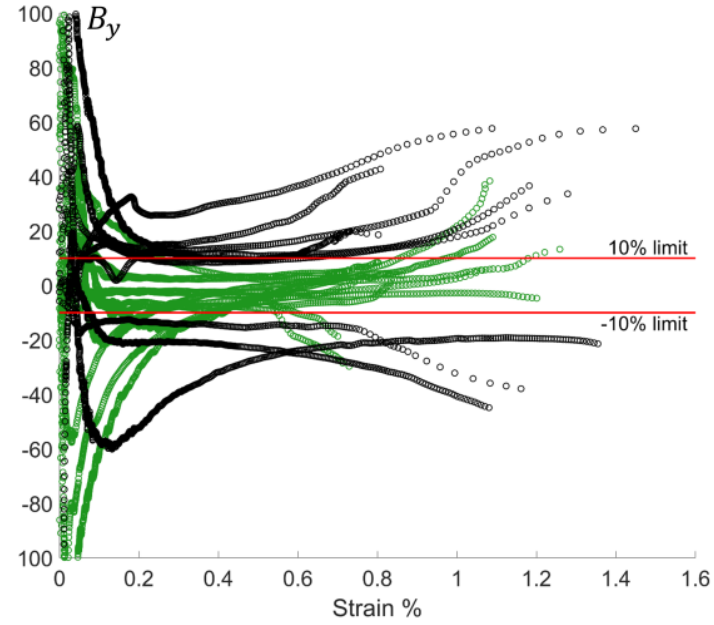

b)

Fig. 14. Results of the compression tests. a) Stress-strain curves and b) bending check for the compression tests: green curves are accepted, black ones are rejected. 
Some of the specimens were accepted even if they were subjected to more than $10 \%$ bending in the very last phases of the test (see green curves in Fig. 14). This is due to the fact that the crossing of the $10 \%$ limit happened after the maximum load was reached.

The stress-strain curves of the valid tests are shown in Fig. 14.a, while stiffness and strength values are reported in Table 4.

Table 4: Compression tests results after rejecting the improper tests.

\begin{tabular}{|c|c|c|c|}
\hline & Modulus $(\mathrm{GPa})$ & Strength $(\mathrm{MPa})$ & Failure strain $(\%)$ \\
\hline $0^{\circ}$ specimens & $38.7 \pm 1.5$ & $261 \pm 17$ & $0.75 \pm 0.06$ \\
\hline $45^{\circ}$ specimens & $25.4 \pm 1.0$ & $192 \pm 21$ & $0.96 \pm 0.10$ \\
\hline $90^{\circ}$ specimens & $17.6 \pm 3.3$ & $192 \pm 24$ & $1.15 \pm 0.08$ \\
\hline
\end{tabular}

It was not possible to perform SEM fractography on compressed specimens: this would have required mechanical separation of the two halves of the broken sample, as it was done for the tensile case. It would have been impossible then to guarantee that any observed feature was caused by the compressive loading and not by the subsequent separation.

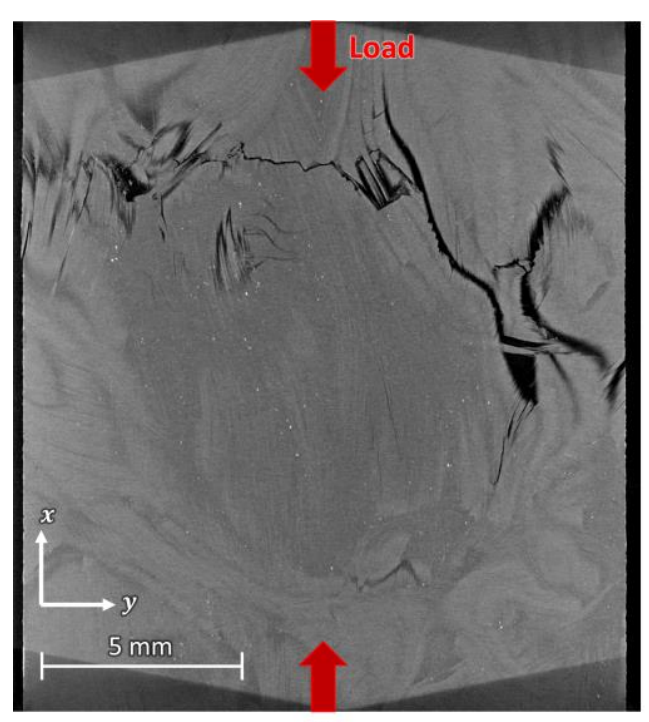

a)

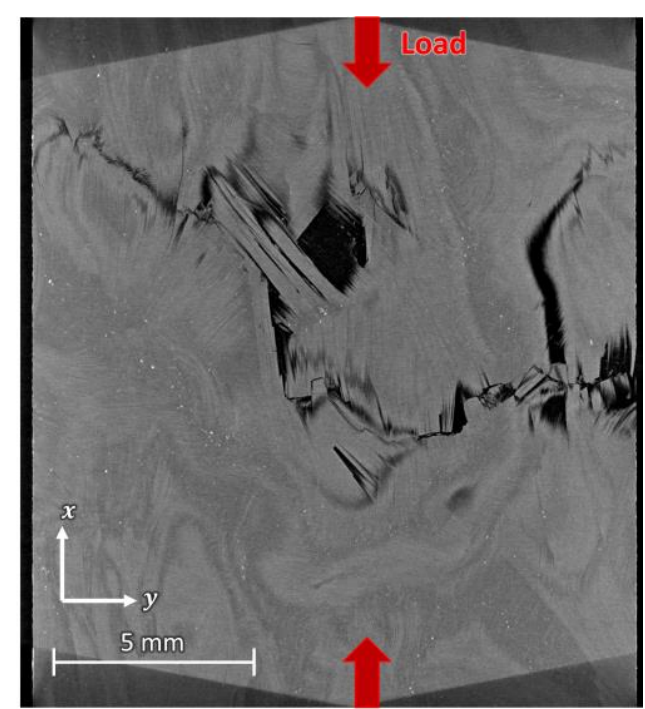

b)

Fig. 15. Examples of in-plane slices of a compression failed $0^{\circ}$ sample. Red arrows indicate load direction.

Straight sharp edges, like those reported in Fig. 15, were commonly observed in the $0^{\circ}$ group. These are intra-tow features, often perpendicular to the tow axis itself. This 
suggests tow failure is caused by local tow buckling along the longitudinal direction of the tow. A higher frequency of these straight sharp edges in the $0^{\circ}$ tows is another confirmation of this hypothesis.

It is worth mentioning that cracks running through tow and matrix, as the ones in Fig. 12 , were commonly observed in both $0^{\circ}$ and $90^{\circ}$ compressive failures. Moreover, this also involved tows oriented parallel to the load direction, as shown in Fig. 16.
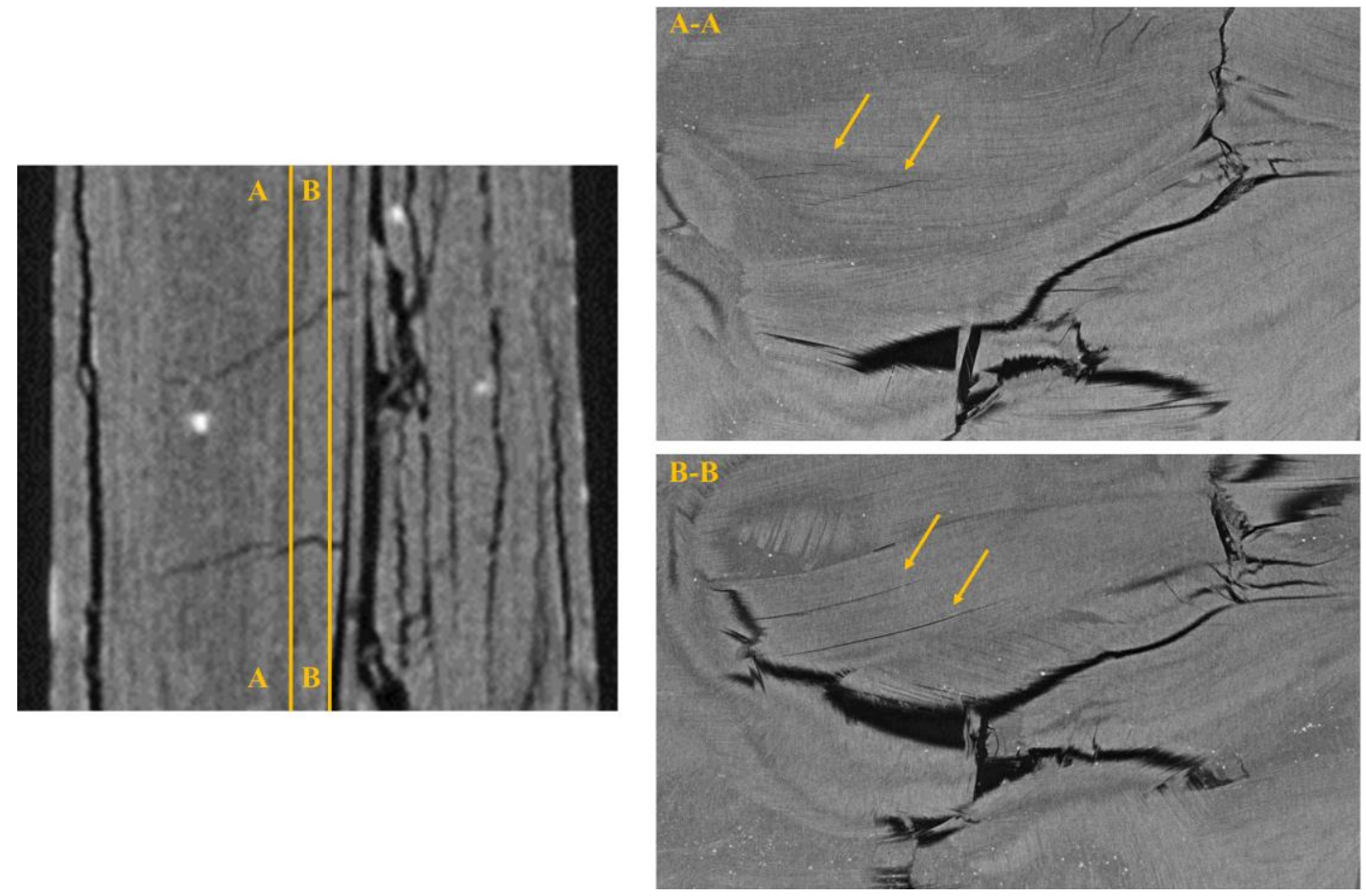

Fig. 16. Split tows in compressive failed samples. The slice on the left is perpendicular to load direction; for the details slices on the right, load direction is horizontal.

Shear cracks were observed in matrix rich areas. Fig. 17 shows an example of such a crack, with the S-shaped profile. Following the indications of Purslow [40], this suggests that the complex microstructure surrounding a resin pocket induces locally shear stress with significant components in all three directions. Note that these shear cracks usually propagate as delamination along the tow interface. 

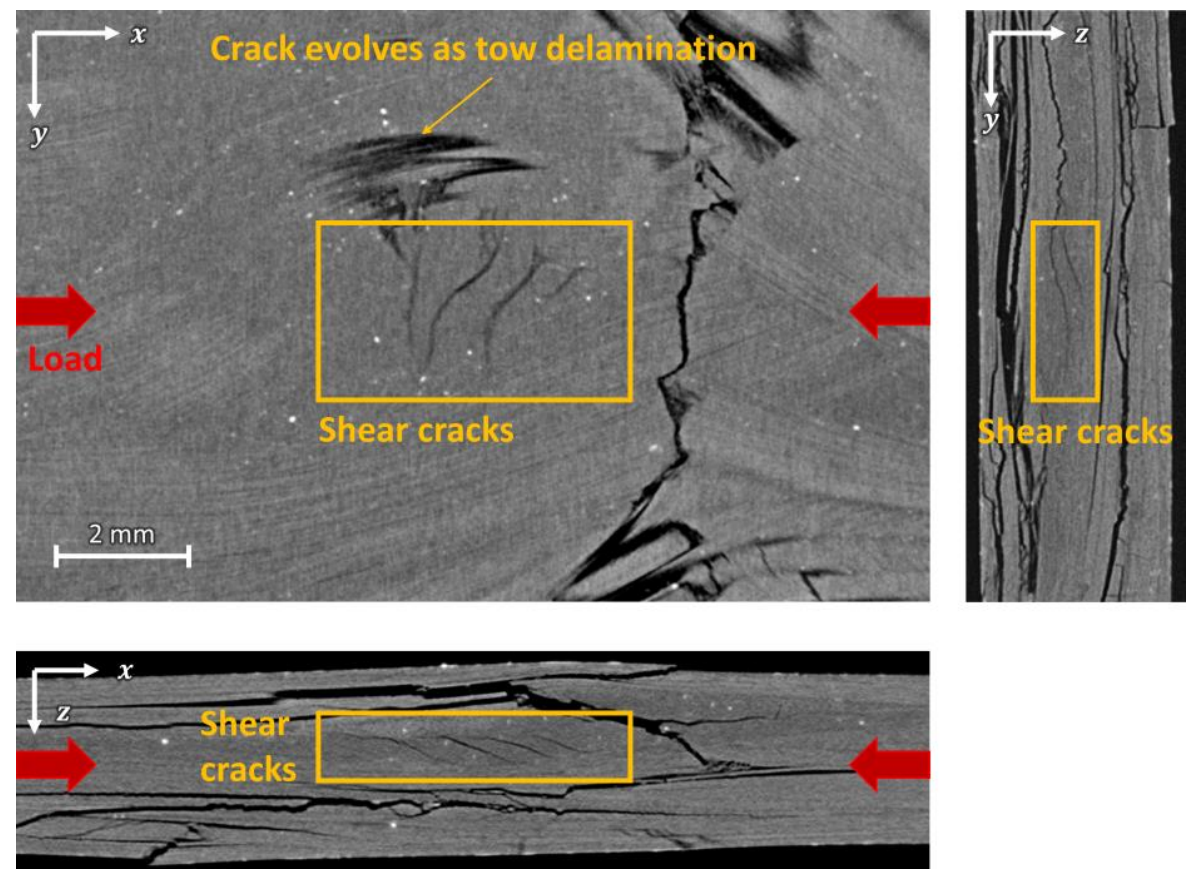

Fig. 17. 3D observation of a shear crack in a $0^{\circ}$ specimen. The crack propagates along the tow boundary as delamination. Red arrows indicate load direction.

\section{Discussion}

\subsection{Fibre orientation dependent failure mechanisms}

It is arguable that Table 3 and Table 4 report lower values of failure strain than those generally observed for fibre and matrix dominated failure. However, this is mainly due to the variability of local structure and properties of the SMC material. In fact, the failure strain that lead to failure was locally much higher. Fig. 18 shows DIC results for two specimens (one $0^{\circ}$ and one $90^{\circ}$ ) immediately before and after failure. For the $0^{\circ}$ specimen, failure occurred at an average strain of $0.683 \%$, but at a local strain of $1.5 \%$, much closer to the $2 \%$ failure strain of the fibres. The $90^{\circ}$ specimen average failure strain was $0.537 \%$, while local maximum value was $3 \%$, high enough to justify a matrix-dominated failure. The strain variability can also be appreciated by looking at the histograms reported next to the scale bars. The proximity of the high-strain region to the specimen's edge is attributed to the material variability and not to the cutting operation. This was confirmed by other specimens that featured more central high-strain regions. 


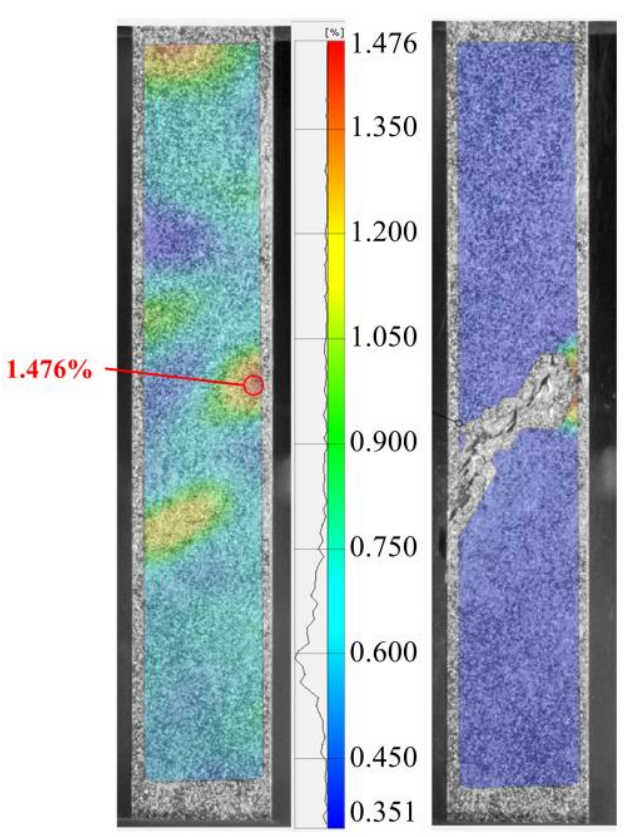

a)

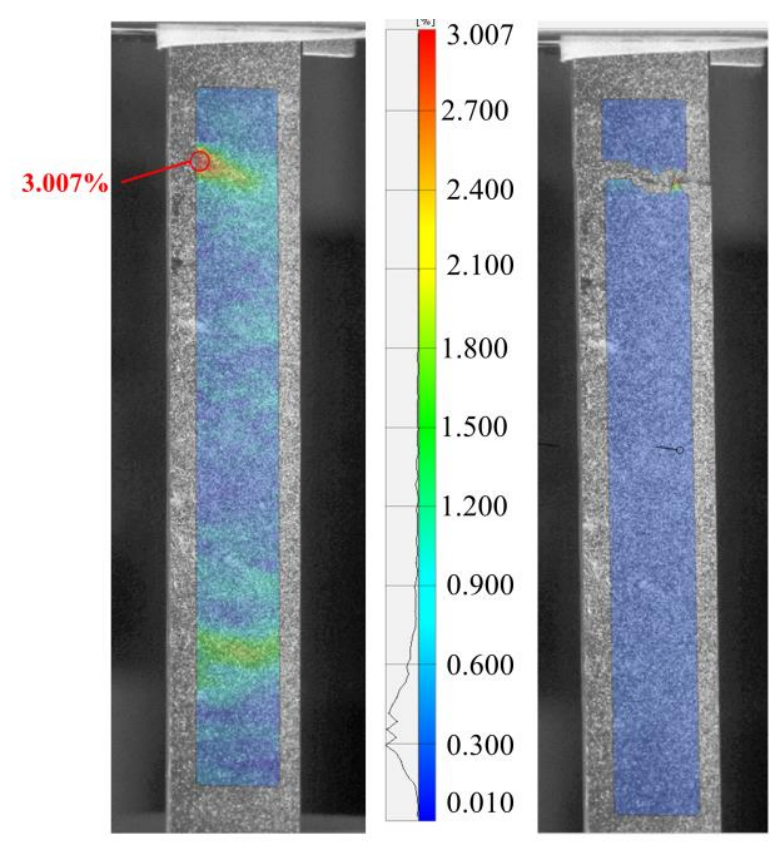

b)

Fig. 18. Maps of the longitudinal strain during the tension tests, immediately before and after failure, for a) a $0^{\circ}$ and b) a $90^{\circ}$ specimen.

Table 2 shows that both failure sections had an orientation tensor component $A_{x x}$ smaller than the one of the overall tensor (with $x$ corresponding to the load direction). A similar behaviour was observed by Denos et al. for randomly oriented SMC in [12]. This means that, in both failure locations, tows were statistically less aligned with the load direction than in the rest of the specimen. Those regions, in fact, are likely to be less stiff than average, thus having higher local strain values and leading to failure easier than other regions (as shown in Fig. 18). In these lower alignment regions, failure occurs at higher strains, according to the prevailing local orientation. For the $0^{\circ}$ case, a local failure strain of around $1.5 \%$ (close to that of the fibres) and a more linear response of the stress-strain curve up until shortly before failure are a further confirmation a fibre dominated failure; when this value of strain is reached, the majority of the tows start to break, fragment and being pulled-out, as observed in Section 4.1.

Moreover, as observed in Fig. 10, CF-SMC was observed to fail far from manufacturing induced defects and cracks. This suggests that the strain concentrations created by misaligned tows are more important than the stress concentration arising from manufacturing defects. Note, however, that other regions with equal or lower $A_{x x}$ also exist in the sample (see Table 2). This suggests that other factors, like presence and orientation of tow ends, also affect the strength of the SMC. A reasonable hypothesis is that such features determine, among the locations with least favourable orientation, the one that will fail. 


\subsection{Difference between tension and compression behaviour}

As shown in Section 4, fibre orientation affects tensile stiffness more than compressive. This suggests that, in tensile tests, the contribution of the fibres is more important than in compression. The matrix plays a more important role in the compressive strength, rather than in the tensile, as well. Indeed, a small difference was observed between the tensile and the compressive strength of the $0^{\circ}$ specimens, while a considerable increase was observed for the other two cases.

Other works on TBDCs [2,8] already observed higher compressive than tensile stiffness and strength, which is unusual for fibre reinforced composites. The discontinuity of the fibres thus has a major role in reducing (or even reversing) the gap between tensile properties and compressive for fibre reinforced composites. However, the main explanation lies on a weaker response of the discontinuous composite in tension rather than a higher one in compression.

Another possible explanation for the higher compressive strength can be found in the material variability. Strain variations are much lower in the compression specimens, since their gauge length is $20 \mathrm{~mm}$, smaller than the length of the tows, which is $25 \mathrm{~mm}$. Therefore, the compressive failure is less likely to be triggered by local strain concentration areas than for the tensile failure. This can be observed in Fig. 19, where DIC results are shown for both $0^{\circ}$ and $90^{\circ}$ case. Interestingly, compressive failure often occurred in the location of the highest strain gradient, instead of the highest strain.

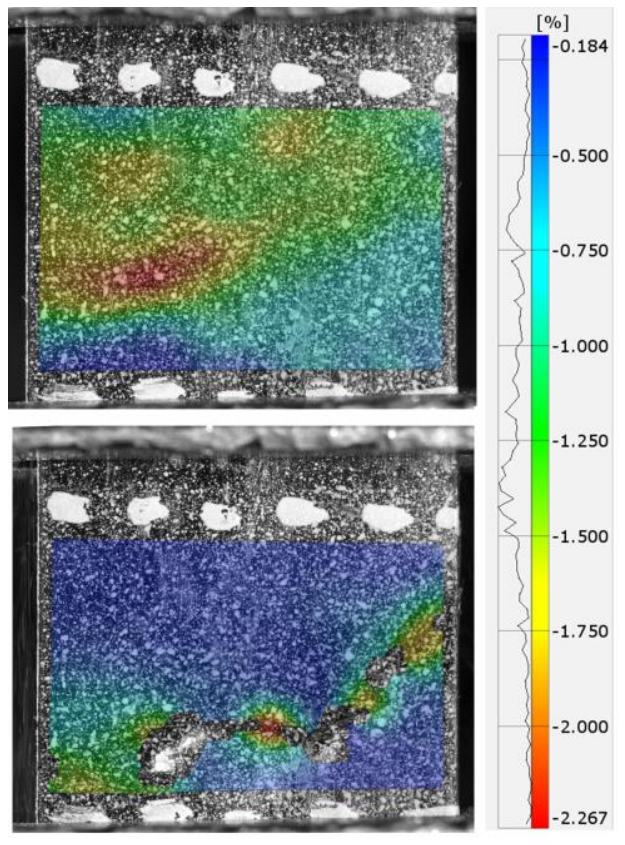

a)

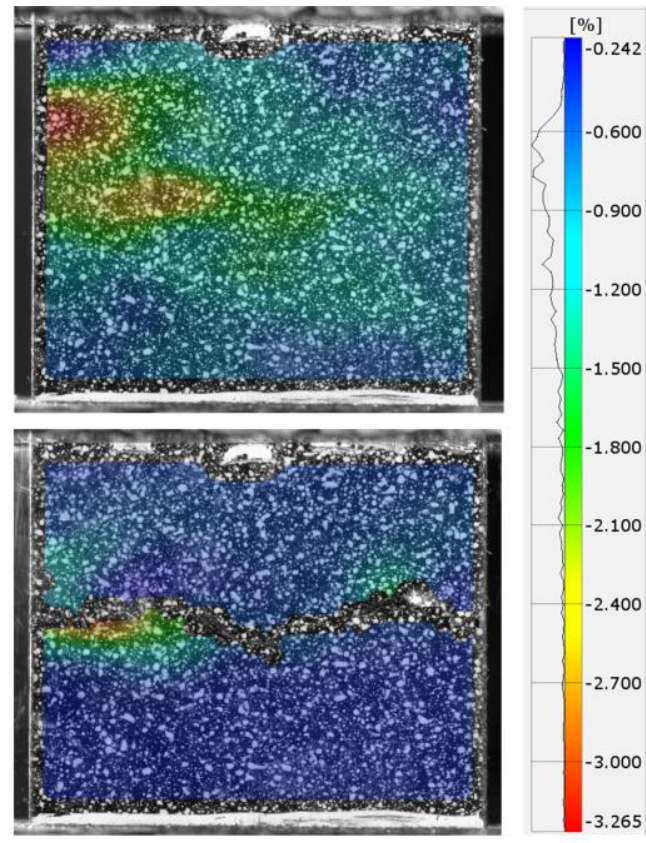

b)

Fig. 19: Maps of the longitudinal strain during the compression tests: images on top show map right before failure; images on the bottom show failure location for the a) $0^{\circ}$ and b) $90^{\circ}$ specimen. 
Regarding compressive failure mechanisms, Fig. 17 has shown the presence of matrix shear cracks and tow debonding. It is reasonable to assume that the failure starts in the matrix undergoing shear, and then propagates through the tow-matrix interface. The cracks keeps propagating until the material is no longer able to sustain the applied load. In addition, in the $0^{\circ}$ case, tows buckling was also commonly observed. Shifting from matrix to fibre dominated failure highlights the major load carried by the reinforcement and explains the higher strength values for the $0^{\circ}$ specimens.

\subsection{Summary of observations}

Manufacturing defects observed with $\mu \mathrm{CT}$ have been reported in Section 3.2. Using both $\mu \mathrm{CT}$ and SEM, features arising due to loading until failure were reported in Chapter 4. All those observations are summarised in Table 5.

Table 5. Defects and failure features observed with $\mu \mathrm{CT}$ and SEM

\begin{tabular}{|c|c|c|}
\hline Feature & Picture & Description \\
\hline Voids & & $\begin{array}{l}\text { Air bubbles trapped inside the } \\
\text { material during moulding. Often } \\
\text { accompanied by other cracks in the } \\
\text { resin (see next feature) }\end{array}$ \\
\hline $\begin{array}{l}\text { Resin } \\
\text { cracking }\end{array}$ & & $\begin{array}{l}\text { Cracks in resin pockets, formed } \\
\text { after manufacturing. }\end{array}$ \\
\hline $\begin{array}{l}\text { Intratow } \\
\text { cracks } \\
\text { (manufacturi } \\
\text { ng) }\end{array}$ & & $\begin{array}{l}\text { Small cracks running inside the } \\
\text { tow, along fibre direction. Probably } \\
\text { fibre matrix debonding. }\end{array}$ \\
\hline $\begin{array}{l}\text { Intratow } \\
\text { cracks } \\
\text { (failure) }\end{array}$ & & $\begin{array}{l}\text { Cracks running inside transverse } \\
\text { tows, created during loading. } \\
\text { Observed mainly for } 45^{\circ} \text { and } 90^{\circ} \text {, } \\
\text { both in tension and compression. }\end{array}$ \\
\hline
\end{tabular}




\begin{tabular}{|c|c|c|}
\hline $\begin{array}{l}\text { Tow pull-out } \\
\text { and breakage }\end{array}$ & d) & $\begin{array}{l}\text { Pulled out and broken tows in } \\
\text { fracture surface of tensile } \\
\text { specimens. Mainly observed in } 0^{\circ} \\
\text { specimens, more rarely in } 45^{\circ} \text { and } \\
90^{\circ} . \text { Pulled-out tows were } \\
\text { frequently also split. }\end{array}$ \\
\hline Tow buckling & & $\begin{array}{c}\text { Tows that buckled locally and } \\
\text { failed. Observed as straight and } \\
\text { sharp edges in failed compression } \\
0^{\circ} \text { specimens. }\end{array}$ \\
\hline $\begin{array}{c}\text { Shear cracks } \\
\text { and } \\
\text { debonding }\end{array}$ & $\stackrel{2}{2}$ & $\begin{array}{l}\text { Shear cracks observed in resin } \\
\text { pockets of tested specimens (not } \\
\text { manufacturing feature). The cracks } \\
\text { would then evolve upon further } \\
\text { loading along the tow interface as } \\
\text { debonding. Observed after both } \\
\text { tensile and compression load. } \\
\text { Observed in all orientations. }\end{array}$ \\
\hline
\end{tabular}

\section{Conclusion}

The effects of a high-flow induced morphology on mechanical response of CF-SMC were studied.

Tows were shown to be highly distorted by the material flow, with higher distortion occurring within $200 \mu \mathrm{m}$ from the outer surfaces of the plates. Despite the high in-plane distortion, a good planarity was preserved, and tows remained mainly $2 \mathrm{D}$ entities. Several manufacturing defects were also observed, mainly in the form of voids and cracks; the last ones were more frequently observed in correspondence of matrix pockets.

The material proved to be insensitive to the microstructural defects observed prior to testing. Strand orientation, instead, proved to be a key factor not only for stiffness, but also for strength. Those showed an anisotropic behaviour, dependent on the strand orientation, both in tension and compression.

Tensile failure often occurred in the regions with a lower-than-average component of the orientation tensor parallel to the load direction. Those regions are indeed likely to be less stiff than the rest of the specimens; failure then occurs at a local strain close to the failure strain of the fibre (for the $0^{\circ}$ case) or of the matrix (for the $90^{\circ}$ case). For the $0^{\circ}$ 
specimens, tow pull-out, failure and splitting were for the first time observed to be the main failure mechanism. Matrix failure and debonding dominated the $45^{\circ}$ and $90^{\circ}$ specimens.

Tow buckling has been observed, for tows mainly aligned along the loading direction, in the $0^{\circ}$ specimens undergoing compressive load. Matrix shear cracks propagating along the matrix-tow interface are believed to be the main failure mechanism in the $90^{\circ}$ specimens.

CF-SMC proved to be a very brittle material. This behaviour is caused by the high heterogeneity of the material: the global failure strain is usually several times smaller than the local strain of the failure site. This must be carefully considered when designing CF-SMC structural parts. Another implication is related to the anisotropic response obtained during testing. The $0^{\circ}$ specimens were $27 \%$ stiffer and $66 \%$ stronger than what is declared by the material supplier for random orientation. However, the randomly oriented material is also declared to be $95 \%$ stiffer and $108 \%$ stronger than the $90^{\circ}$ specimens. The stiffness and strength of the $45^{\circ}$ specimens were also found to be smaller than what declared by the supplier. The loss of mechanical properties for the transverse case is higher than the gain obtained in the aligned case. Therefore, TBDCs with significant preferential orientation should only be considered for applications in cases of clearly defined prevailing loading directions.

\section{Acknowledgements}

The research leading to these results has been performed within the framework of the FiBreMoD project and has received funding from the European Union's Horizon 2020 research and innovation programme under the Marie Skłodowska-Curie grant agreement No 722626. YS acknowledges FWO Flanders for his postdoctoral fellowship. SVL holds the Toray Chair at KU Leuven, the support of which is acknowledged. SP acknowledges her Research Fellowship of the Royal Academy of Engineering on "Multiscale discontinuous composites for high-volume and sustainable applications" (2015-2019). The authors also acknowledge Mitsubishi Chemical Carbon Fiber and Composites $\mathrm{GmbH}$ for providing material and related information. The micro-CT images have been acquired on the X-ray computed tomography facilities at KU Leuven, maintained under the supervision of Prof M. Wevers and financed by the Hercules Foundation and the Research Council of KU Leuven (project C24/17/052); help of Dr Jeroen Soete and of technician Johan Vanhulst is gratefully acknowledged. The authors acknowledge Marco Alves (Imperial College London) for several useful discussion on $\mu \mathrm{CT}$ analysis of TBDC. The technicians of KULeuven Bart Pelgrims and Kris Van de Staey are acknowledged for their help with the tensile and compressive tests. 


\section{References}

[1] Visweswaraiah SB, Selezneva M, Lessard L, Hubert P. Mechanical characterisation and modelling of randomly oriented strand architecture and their hybrids - A general review. J Reinf Plast Compos 2018;37:548-80.

[2] Selezneva M, Lessard L. Characterization of mechanical properties of randomly oriented strand thermoplastic composites. J Compos Mater 2016;50:2833-51.

[3] Chang IY, Pratte JF. LDF ${ }^{\mathrm{TM}}$ Thermoplastic Composites Technology. J Thermoplast Compos Mater 1991;4:227-52.

[4] Tucker CL, Liang E. Stiffness predictions for unidirectional short-fiber composites: Review and evaluation. Compos Sci Technol 1999;59:655-71.

[5] Wan Y, Takahashi J. Tensile properties and aspect ratio simulation of transversely isotropic discontinuous carbon fiber reinforced thermoplastics. Compos Sci Technol 2016;137:167-76.

[6] Kelly A, Tyson WR. Tensile Fibre-Reinforced Metals : Copper/Tungsten and Copper/Molybsenum. J Mech Phys Solids 1965;13:329-50.

[7] Barbero EJ. Introduction to Composite Materials Design. 2nd ed. Taylor \& Francis Group; 2011.

[8] Feraboli P, Peitso E, Deleo F, Cleveland T. Characterization of Prepreg-Based Discontinuous Carbon Fiber / Epoxy Systems. J Reinf Plast Compos 2009;28.

[9] Feraboli P, Peitso E, Cleveland T, Stickler PB. Modulus measurement for prepreg-based discontinuous carbon fiber/epoxy systems. J Compos Mater 2009;43:1947-65.

[10] Evans AD, Qian CC, Turner TA, Harper LT, Warrior NA. Flow characteristics of carbon fibre moulding compounds. Compos Part A Appl Sci Manuf 2016;90:112.

[11] Nicoletto G, Riva E, Stocchi A. Mechanical Characterization of Advanced Random Discontinuous Carbon/Epoxy Composites. Mater Today Proc 2016;3:1079-84.

[12] Denos BR, Kravchenko SGS, Pipes RBB, Pipes B. Progressive Failure Analysis in Platelet Based Composites Using CT-Measured Local Microstructure. Int SAMPE Tech Conf 2017:1421-35.

[13] Johanson K, Harper LT, Johnson MS, Warrior NA. Heterogeneity of discontinuous carbon fibre composites: Damage initiation captured by Digital Image Correlation. Compos Part A Appl Sci Manuf 2015;68:304-12.

[14] Piry M, Michaeli W. Stiffness and failure analysis of SMC components considering the anisotropic material properties. Macromol Mater Eng 2000;284285:40-5.

[15] Yamashita S, Hashimoto K. Experimental characterization of the tensile failure mode of ultra-thin chopped carbon fiber tape-reinforced thermoplastics 2016. doi:10.1177/0731684416651134.

[16] Wan Y, Takahashi J. Tensile and compressive properties of chopped carbon fiber tapes reinforced thermoplastics with different fiber lengths and molding 
pressures. Compos Part A Appl Sci Manuf 2016;87:271-81.

[17] Wan Y, Straumit I, Takahashi J, Lomov S V. Micro-CT analysis of internal geometry of chopped carbon fiber tapes reinforced thermoplastics. Compos Part A Appl Sci Manuf 2016;91:211-21.

[18] Wan Y, Straumit I, Takahashi J, Lomov S V. Micro-CT analysis of the orientation unevenness in randomly chopped strand composites in relation to the strand length. Compos Struct 2018;206:865-75.

[19] Feraboli P, Peitso E, Cleveland T, Stickler PB, Halpin JC. Notched behavior of prepreg-based discontinuous carbon fiber/epoxy systems. Compos Part A Appl Sci Manuf 2009;40:289-99.

[20] Qian C, Harper L, Turner TA, Warrior NA. Notched behaviour of discontinuous carbon fibre composites: Comparison with quasi-isotropic non-crimp fabric. Compos Part A Appl Sci Manuf 2011;42:293-302.

[21] Pimenta S, Ahuja A, Lau AY. Damage Tolerant Tow-Based Discontinuous Composites. 20th Int Conf Compos Mater 2015:19-24.

[22] Folgar F, Tucker CL. Orientation Behavior of Fibers in Concentrated Suspensions. J Reinf Plast Compos 1984;3:98-119.

[23] Bay RS, Tucker CL. Fiber orientation in simple injection moldings. Part II: Experimental results. Polym Compos 1992;13:332-41.

[24] Le TH, Dumont PJJ, Orgéas L, Favier D, Salvo L, Boller E. X-ray phase contrast microtomography for the analysis of the fibrous microstructure of SMC composites. Compos Part A Appl Sci Manuf 2008;39:91-103.

[25] Advani SG, Tucker CL. A numerical simulation of short fiber orientation in compression molding. Polym Compos 1990;11:164-73.

[26] Denos BR, Sommer DE, Favaloro AJ, Pipes RB, Avery WB. Fiber orientation measurement from mesoscale CT scans of prepreg platelet molded composites. Compos Part A Appl Sci Manuf 2018;114:241-9.

[27] Kite SF, Nixon-pearson O, Ogin SL, Jesson DA, Hamerton I, Sordon A, et al. Effect of charge placement on fibre orientation, distortion and failure of a carbon fibre reinforced sheet moulding compound. ECCM 18, Athens: 2018.

[28] Nony-Davadie C, Peltier L, Chemisky Y, Surowiec B, Meraghni F. Mechanical characterization of anisotropy on a carbon fiber sheet molding compound composite under quasi-static and fatigue loading. J Compos Mater 2018.

[29] Straumit I, Lomov S V., Wevers M. Quantification of the internal structure and automatic generation of voxel models of textile composites from X-ray computed tomography data. Compos Part A Appl Sci Manuf 2015;69:150-8.

[30] Mitsubishi Chemical Corporation. Pyrofil STR120 datasheet n.d.

[31] Mitsubishi Chemical Corporation. TR50s Datasheet n.d.

[32] Advani SG, Tucker CL. The Use of Tensors to Describe and Predict Fiber Orientation in Short Fiber Composites 1987.

[33] Tseng H-C, Chang R-Y, Hsu C-H. An objective tensor to predict anisotropic fiber orientation in concentrated suspensions. J Rheol (N Y N Y) 2016;60:215- 
24.

[34] ASTM. Standard Test Method for Tensile Properties of Polymer Matrix Composite Materials 2010;i.

[35] ASTM. Standard Test Method for Compressive Properties of Polymer Matrix Composite Materials with Unsupported Gage Section by Shear 2011;03:1-16.

[36] Bogetti TA, Gillespie JW, Byron Pipes R. Evaluation of the IITRI compression test method for stiffness and strength determination. Compos Sci Technol 1988;32:57-76.

[37] Straumit I. Prediction of the Effective Properties of Textile Composites based on X-ray Computed Tomography Data. KULeuven, 2017.

[38] Odenberger PT, Andersson HM, Lundström TS. Experimental flow-front visualisation in compression moulding of SMC. Compos Part A Appl Sci Manuf 2004;35:1125-34.

[39] Ferré Sentis D, Orgéas L, Dumont PJJ, Rolland du Roscoat S, Sager M, Latil P. 3D in situ observations of the compressibility and pore transport in Sheet Moulding Compounds during the early stages of compression moulding. Compos Part A Appl Sci Manuf 2017;92:51-61.

[40] Purslow D. Matrix fractography of fibre-reinforced epoxy composites. Composites 1986;17:289-303. 